\title{
A Road Map For Applying Relational Sociology
}

\author{
Aytul Kasapoglu \\ Department of Sociology, \\ Baskent University. Turkey
}

\begin{abstract}
Relational sociology is based on the French and the German who first came to mind. It is important to note that Bourdieu and Elias are an introduction to relational sociology, although in the last 30 years different opinions or voices have been heard from America and Europe. For this purpose, following the process-based sociology of Bourdieu and Elias, Kivinen and Piiroinen (2013) were given to emphasize epistemology rather than ontology and to make it clear from metaphysical consideration. On the other hand, the work of White and his colleagues (2013) was handled in detail to represent relational sociological studies in the United States. As a result, the theoretical foundations of relational sociology under the metaphorical titles of three from Europe and one from America were tried to be explained in detail. In the conclusion part, relational sociology was made clear with some tables.
\end{abstract}

Key words: Relational sociology, epistemology, Turkey.

\section{INTRODUCTION}

In both classical and contemporary sociology, social relations have a privileged place in terms of understanding socio-cultural processes. Thus, in recent years, the evaluation of the systematic work of sociologists in the field of "relational sociology" has gained importance. Among the studies conducted in the last 30 years in the name of relational sociology, the first order is Italian Pierpaolo Donati and his "Introduction to Relational Sociology" (1983) and "Social Relations Theory" (1991). However, PierpaoloDonati's (2011) argument that relational sociology is a new paradigm in social sciences has taken its place in history with violent criticism. After the first initiatives of European origin, Canadian Harrison White (Identity and Control, 1992) and Crimean-based American Mustafa Emirbayer (Relational Sociology Manifestos, 1997) have to be remembered. Following them are Nick Crossley (Towards Relational Sociology, 2010) and Margaret Archer (The Reflexive Imperative in Late Modernity, 2012) and François Depelteau and Christopher Powell (2013). Of course, it is not possible that all of the existing studies are regarded as relational sociology. It is possible to talk about different conceptualizations such as "transactional" or "figurational". What is important in this context is to clarify similarities and differences between these different relational sociologies. There is no doubt that the existence of ensembles with different relational approaches, and their comparison, will in fact reveal the potential capacity of this approach.

Despite the fact that the first steps are taken in Europe, it is not unlikely that an important leap came from the United States. Because those who call mini-conferences and workshop-type studies to create opportunities for conversation and debate in New York in the 1990s, and even those that assessed even the PhD thesis committees for that purpose, and thus are referred to as "public," inspired by Goffman, include Harrison White and Charles Tilly as well as younger excited students as well as senior sociologists. As R. Collins (1998) points out, these people are a source of energy and excitement for a network in which democratically 
discussing intellectual opposition such as positivism and interpretivist sociology. The most important thing that emerges in this fruitful talk and argument is the formation of a network of relationships to understand dynamic social processes rather than a single or original theory. Because until the 1990s, the dominant positivist understanding in network analysis was neglecting the interpretation and construction of meaning as it was far from the concept of cultural richness because of the heavy influence of the mathematical direction.

On the other hand, The American Sociological Association's (ASA), the formerly marginalized cultural section, is also beginning to expand and in the mid-2000s, "cultural sociology" studies this area, which often overlaps with subfields such as political sociology, comparative historical studies, social movements and collective behaviour- becomes the most sophisticated field of study. The relation-network analyses of important sociologists such as Bearman(1993), Mohr(1994) and Erikson(1996) that pioneer the understanding of cultural and historical processes draw attention .

For relational sociology, "New School for Social Research" in New York and C. Tilly and then M. Emirbayer sociologists were the first to come to mind. Because in the 1980s the university administration employed famous thinkers such as C. Tilly and E. Hobsbawm, allowing intensive discussions between critical theorists, structuralists and post-structuralists to create new approaches. Indeed, in this productive environment, C. Tilly came to a synthesis called "relational realism" by observing his current views on identity, narrative and discourse. M. Emirbayer, who later became an assistant professor to the New School in 1991 and was interested in the interpretivist sociological tradition while working at Harvard University theManifesto of Relational Sociology is written by him in 1997.

A more systematic and theoretical (especially ontologically accented) relational sociology literature than the previous ones has become popular in the USA and Europe in recent years, with the claim that it is a new paradigm and the practice examples. For example, Emirbayer (1997), White (1998; 2013) and Mohr (2005; Powell and Depelteau (2013) Depelteau and Powell (2013) also draw attention in Canada; sociologists such as Tsekeris (2010), Kivinen and Piiroinen (2012), Kaspersen (2011) and Fuhse (2013) have begun to be mentioned in Europe.

In Turkey, efforts to promote this trend and translation-based debates have started (Göker ve Çeğin, 2012; ÇeğinveEsgin, 2015). On the other hand, while the presence of competing views rather than a single relational theory undermines the claim of being a new paradigm, the risk of drowning in sociology, philosophical debates, has increased in parallel with the ontological orientation of the subject being treated more heavily. Here is, it should be especially mentioned that this article is written with more scientific preferences by being tried to stay at epistemology level to prevent the intervention of philosophy to sociology with the ontological arguments.

Consciously the focus of this manuscript is on epistemological and therefore methodological concernes of relational sociology. For this reason it was shown that there were relational sociological studies from Europe (P. Bourdieu, N. Elias and O. Kivinen\& T. Piroinen) and USA (H. White and et al.) and the results are summarized in tables.

In fact, it should be underlined that the core staff of the discussion group that can be called a team were my students and the discussions took almost two years in the form of workshops in and out of my doctorate courses in the Department of Sociology of Faculty of Letters at Ankara University. Moreover, the only reason why our modest workshops, which can not be compared with the environment of the 1990s in America, are shared with readers by giving 
fruitful results; in Turkey, to show that the "epistemic communities" can be established when it is needed. Risk and trust are like the two sides of the same money, and it is necessary to control it to get rid of ambiguity as H.White (2013) points out. We have probably taken a risk to see how much we can grasp the theretical discussions of relational sociology, but our colleagues and related readers will decide whether or not it is worth it.

\section{PREVAILING WINDS FROM EUROPE 1 : P.BOURDIEU AND RELATIONAL SOCIOLOGY}

Bourdieu, as a sociologist, although he has a lot of followers, has not escaped the target of criticism. When Bourdieu is assessed in relation to relational sociology in this subsection, it should be particularly noted that John Mohr's (2013) criticism is followed. Thus, shown how the criticized aspects of Bourdieu were surmounted. John Mohr is a professor of sociology at Santa Barbara University in the USA / California. Mohr, examines systems of institutional discourse and articulation of these dualities in a relational sociological way. It should be remembered that opposition to dualities and articulations is the main distinguishing feature of relationalism.

One of Bourdieu's still-important views today is that sociologists must adopt a relational approach rather than a substantialist approach. According to Bourdieu (1998), the essencialist approach focuses on "things" rather than relationships. It also tends to reify social order and come to the core of social phenomena. Apart from all these, it is positivism oriented when doing social research. Because of this, Bourdieu rejects essentialism and prefers relational analysis because it carries these features. This means seeing the examined subject contextually as a part of the whole. For him, the meaning of the subject / object is not determined by its essence, its distinctive features and qualities. Instead, meaning is derived from the "field", practices or activities that are embedded within the subjects / objects (Bourdieu,1998).

According to Mohr (2013:102), Bourdieu's relational analysis is important for three reasons. These are:

a) Contributing to the development of the "structuralist" style of interpretation,

b) to emphasize the interpretive nature of institutional life,

c) provide a strong framework for the analysis of institutional dualities. It is the effort to overcome individual-society dualities. For this purpose, he tries to establish a connection with cultural forms of social positions by adding cultural analysis. But according to Mohr, Bourdieu's theory is always more successful than he does in practice.

Mohr (2013) focuses on how Bourdieu has made relational theory work for this purpose. The impression he gets from here is ironic. Because although his method is important enough to be taken as an example from certain directions, he rarely uses it.

Mohr (2013:102) actually makes very important evaluations. In his view, it is clear that Bourdieu has analyzed data that he has failed to relationally look at, which he expects from other social scientists, and which he collects with more deterministic straight line logic. In other words, Bourdieu itself is determined by the linear / straight line style. For this reason, the linear analysis, also called "dimensionality", may be a better indication of social and cultural processes than Bourdieu's relational theoretical view. Mohr (2013:102) therefore underscores the importance of topological thinking, saying that instead of Bourdieu, it is necessary to turn to institutionalists or new social network theorists. Mohr (2013) thus believes that the concept of "field" is better understood. To go beyond the Bourdieu's "cultural field" theory and to study the field theory itself we have to ask following questions : "What is the field really?", "How a field works ", "How can we examine and measure fields in space." For 
this purpose, Mohr examines the thoughts of Kurt Lewin, a German-born psychologist, who worked on field theory many, many years ago. Moving from the connections between contemporary thinkers and Lewin, he suggests a model of how to map the cultural field topologically with relational logic.

In recent years it has been observed that interest in Bourdieu and his basic concepts such as field, capital types and habitus has increased considerably. Numerous people share Bourdieu's belief in making both relational-based social science and field theory. His ideas and approaches are therefore being moved into many different and new research areas (Breiger, 2000; Calhoune et al., 1993).

Bourdieu's relational understanding is based on French structuralism, while rejecting analyzes in substancist style. As he wrote in his autobiography, he is influenced by the structuralism of Levi Strauss from the earliest days and by the view that Ferdinans Saussure's language is completely relational (Caws, 1988). He recognizes that the signifier and the signified relation, which is the basis for semiotic studies such as Saussure, is also arbitrary. Structuralism, as Caws (1988) points out, is not ansubstantialist in the realities of social sciences and human beings, but rather a relationalist view. In this context, the most fundamental characteristic of structuralism is that it is also a critical "method" for determining and investigating relations sets or structures. Bourdieu is influenced both by Cassierre $(1910 ; 1953)$ at a young age and by Sauussure's terms, learns that similarities and differences emerge in the relational system and that the meaning is arbitrary (cited in Mohr,2013:103-104).

These structural roots in early Bourdieu's have led other consequences . For example, Bourdieu tried to interpret the cultural meaning by "hermeneutic" whatever the topic studied. According to Bourdieu, all institutions should be studied in the same way as language. These features show that social science practice, which he embraces, is structuralist theory. Structuralism actually has the characteristics of formal methods and is in harmony with them. In fact, Bourdieu's social awareness of collecting quantitative data is greater. However, according to Mohr (2013:104), his bringing together his self-reflexive theoretical stance and empirical data accumulation further increases the demands and applications to him.

According to Mohr (2013:104), Bourdieu treats cultural forms as objects of empirical analysis in his relational sociology conception. As a result, the structural and relational legacies that he possesses have intertwined in Bourdieu, leading him to develop his own approach to the study of institutional life meaningfully within social and cultural fields.

On the other hand, it is important to note that it is not possible to say that Bourdieu's work is fully structural. Because the work of sutractialistslike Levi-Strauss, Lacan, and Barthes is very different. In addition, structuralists have greatly criticized post-structuralists such as Derrida.Post structuralistshave used the "deconstruction" method to show how the meanings of sacred texts can be altered. Bourdieu,has remained uninterested to the post-structuralist winds in the social sciences and attempted to develop his own method.

Bourdieu (1977) began to construct his theory when conducting field studies in Algeria, and the "Theory of Practice" emerged as a theoretical approach to the study of the culture. Bourdieu's approach to this work quite well describes the need to confront the duality between agency and institution and to struggle to overcome this difficulty. He is aware that this struggle is the core of human life and is important for social sciences. Theory of practice, on the other hand, is also very important for empirical social science because it provides the basis for the structuralist defending the fixed meaning of texts. The fact that the meanings are derived 
from the practical actions they are in is based on the idea that their meanings may change as the actions in the material and sensual world change. According to him, meanings live in the world because they originate from the practical materiality of life. This view is not only theoretical but also methodological. According to Mohr (2013:105), Bourdieu, practical maneuver, escaped the bonds of structuralism.

Bourdieu (1977), through his interpretative approach to "Practice Theory", provides practical reasoning to show that certain meanings are more valid, meaningful, and empirically measurable than others. Because, according to him, meanings are connected to each other through forms of practice that allow differences to be seen as meaningful. Bourdieu, according to Mohr (2013:105), provided some basic contributions to formal social science practice as well as cultural understanding in this maneuver.

According to Mohr (2013), Bourdieu does not think that ideas are determined by material. On the contrary, he accepts that the idea and the material form mutually interdependent. For example, practices are equally dependent on both understanding and knowing. Engagement in practice means always putting the framework of understanding, a set of considerations and a cultural text on a floor. The thought of the combination of cultural and practical completes the transformation of Bourdieu from the structuralistmethod to his own understanding of relational sociology. Education is meaningful because life in institutions such as the state and the family is practical. Because they are both out of differences and practices. Finally, a third sign of Bourdie's adoption of relational thinking is his statement, "If institutions are to be read like language, it is possible to address them in the text of institutional practice, that we will be able to crack the code (Cited in Mohr,2013:106. " It is here that the concept of structuralism is replaced by the notion of "Theory of Practice" which is based on difference and change.

It should be known that Bourdieu is not only interested in relational sociology theoretically, but also in practice. It should not be forgotten that he made extensive theoretical contributions based on his empirical studies. One example of this is the relationship between cultural capital and class structure. He and his colleagues have studied critically about the fact that the system based on educational stratification in France is not objective. According to Bourdieu, the French education system is not an objective and unbiased system, because of the class hegemony in Marxist sense. On the contrary, according to Bourdieu, the French education system is a system that is awarded to those who learn the elusive cultural aspects of nuances, albeit not explicitly. In other words, it is possible for learners who learn elite culture and details in good schools to gain more respect in their future lives, reach intellectual resources and institutional success, while the opposite is true for the other broader (Bourdieu and Passeron, 1977).

According to Mohr (2013:106), Bourdieu's work on cultural capital allows us to understand how he studies and interprets institutions. The meaning comes out exactly here. Because students gain cultural capital in their schools; they share meaning with their teachers and other intelligent and reliable mentors. The task of education is to ensure that students are familiar with the form and content that high cultures can provide, and thus show some sort of cultural refinement. Certainly there is a social process as well as intellectual mastery here. According to DiMaggio and Mohr (1985), which criticize Bourdieu's work, it is also the case that students with high cultural capital can easily identify with and internalize these elemental institutional systems.

The best example of how Bourdie deals with economic classes and culture is his work on the educational institution. If this cult produces an objective output, which is to show that if one 
succeeds in education, the future class position will also be high. In other words, culture here is producing social structure. However, according to Bourdieu, the social class also produces culture in the same way. Because social classes have different cultural habitus and have cultural capital that affect institutional success.

Mohr (2013:107) examines how Bourdieu's research practice is and how he collects data. For example, his most important work, "Distinction" is on. In this study, Bourdieu examined the relationships between social classes and judgments of taste in France through diagrams. In this study, Bourdieu used survey data from the field to explain the relationship between social classes and cultural tastes. Bourdieu (1984) notes that it is not easy to construct these diagrams. Because it is necessary to avoid being one-sided and biased and to show the network of all relations. To overcome these difficulties, it is clear that Bourdieu looks at the "correspondency" between the social structure and the social space, taking advantage of the semiotician Ferdinand Sauussure. This approach is to take the "social space" and the "capital" together, in which the symbolic features are loaded (Bourdieu, 1984:96).

Bourdieu, despite his complaint, points out that all associations like Saussure need to address the network together. It also describes "correspondence" between social space and symbolic space. This is also the name of the method, "Reciprocity Analysis" here comes from. Bourdieu prefers this method to multivariate regression analysis. The reason for this preference is to show the reality of the social world better as a relational technique in the analysis of data. Bourdieu says he finds in this technique what he wants to do exactly with the notion of "field".

Ronald Breiger (2000;2009) is one of the experts of the Reciprocity Analysis. He compares the official assumptions of the Reciprocity Analysis with those of other such analysis arguments. For this purpose, he examines the statistical relationships between the categories in the rows and columns. According to Breiger, the key issue is the "duality" notion. Breiger defines this as co-occurrences or co-constitutions of elements at different levels. In other words, it means that one structure constitutes the other and the other constitutes it (and vice versa). What Breiger wants to remind us is that Bourdieu is constantly interested in mapping such binaries. For example, Bourdieu, in the secondary school where the girls of the elite go, compared their father's occupation. What Bourdieu wants to do here, using his own method, to show how the two different qualities and features are incorporated in a common structure.

It can be said that a large part of Bourdieu's model is perfect (Mohr, 2013). Because the model shows the cultural and economic capital of different groups' social places. Bourdieu calls them "class fractions" within the area on which each group is based. His figures carry quite Saussurean orientations. It is assumed that cultural aspirations have a given cultural meaning derived from similarities and differences that define the system of all likes within the broader system at the same timel. In this context, the main feature of the tastes is simply different from all other cultural favorites (Bourdieu, 1984).

Bourdieu shows the place map of the cultural tastes and classes as duality in the same measurement field. His studies on education indicate his emphasis on duality. In other words, class and culture are reciprocally related. While a person's class place is defined by his cultural affiliation, the culture of a person is likewise defined by his class position within the social organization. According to Mohr (2013), the theoretical vision of Bourdieu is very consistent with the practice.

Bourdieu wants to show us two dimensions. In the vertical dimension, there are all kinds of economic and cultural capital from high to low. The horizontal dimension includes all the 
components of economic and cultural capital. Those in the upper left are those with high cultural capital but low economic capital. For example, professors in higher education and teachers in secondary education, art producers, managers in the public sector are in this upper left section. On the other hand, the right superstates are those whose economic capital is high but the cultural capital is low. These include businessmen, company managers in the private sector, and engineers. To summarize, the right and left upper layers represent the social places of different groups. It must be remembered that Bourdieu called these "class fractions".

Mohr (2013:110) quite rightly thinks that Bourdieu's concept of "field" is important, because the cultural capital that Bourdieu had dealt with in his previous work, and the French lifestyle that he later studied after the educational stratification, and so on to the rest, are all institutional fields. Bourdieu (1983; 1985; 1987; 1991) defines the concept of field as "relatively autonomous social microcosms" in response to regions of institutional life. Then give field examples. These include art, academy, religion and law. According to Bourdieu and Wacquant (1992), each field is defined by social relationships or social locations. In addition, each space consists of "spaces of objective relations" in the sense of logic and necessity. All of this is important for Bourdieu's attention to the positivist and objective aspects. More precisely, it is sociologically very remarkable that it is about producing objective information.

Bourdieu actually sees the duality between culture and practice. Because, according to Bourdieu, one's position within the field is determined by the relations in the system of meanings that function as the stock of field-specific capital. At the same time, the system of meanings that form the basis for the action of habitus within the field was itself defined by individuals and groups. This means that individuals and groups also have the power to shape the countours and features of the meanings within the field, and it is extremely important. According to Bourdieu (1987), each field is a place where some types of capital operate. This also means that all individuals, classes or professions are assessed according to their relative positions within the field, as area-specific capital owners. This resource also shows the power and success they have in a particular institutional sphere. Groups and individuals struggle in the field in order to obtain objective locations to determine which meaning is legitimate. For example, the field of law is the place where you are competing to obtain the monopoly of law. All these features show that Bourdieu is at the same time a thinker who represents conflict sociology. In short, space and relationality are extremely helpful in telling the conflicting parties and the place of conflict.

Mohr (2013:111) notes that Bourdieu is criticized by many, including himself. According to him, his difference from the others is, as mentioned before, more concerned with practice. Because Bourdieu's theoretical orientation is extremely impressive. Mohr's (2013:111)critique is related to the data analysis technique that Bourdieu uses when applying relational theory. According to Mohr, if we accept the duality of culture and practice, we can not criticize Bourdieu's method and theory.

Therefore, Mohr (2013), who returned to the method part again, tries to explain his criticisms on Bourdieu's works. According to him, the model shown by the figures has many good features. The model assumes that the institutional is an internally significant space. On the other hand, when considering the system of differences between social locations and social life styles, it refers to the structuralist method of interpretation. Because of the duality of culture and practice, it is argued that class fractions are determined by cultural tastes and that cultural taste differences are determined by social classes. The biggest problem in the model and analyzes is that similarities are always defined by straight linear relations, and other features of phenomena are measured as similarities and differences. Thus, in this model there are two 
dimensions, one of capital volume and the otherof capital compositions. Here, Mohr (2013) finds this problematic in two respects.

First, according to Mohr (2013:112), other cultural logics and trends are not in the space of measurement. All people, irrespective of who they are and where they are, have been assessed according to their degree of cultural styles and knowledge formations determined by the elite class fraction. Mohr (2013:112) believes that Bourdieu uses this metric system in a highly councouslyway to show how power emerges in the field. According to Mohr, other modes of cultural mastery and other communicative knowledge styles or culturally specific skills are not included in this model. Their absence weakens his model at the point of how cultural systems are organized. Because only cultural capital remains.

According to Mohr (2013), in this case the field is entirely driven by the logic of struggle to determine the space dimensions at the macro level. In other words, this is a struggle for one to settled within the system of dominant culture and discourse. Other conflicts, other engagementsand in particular other local challenges and positions related to resources have not been taken into account in this model. However, many recent research has shown that this local fight and competition is also important (Fligstein and McAdam, 2012). Other factors, not just the dominant forms of capital, need to be included in the analysis. Indeed, a more adequate or complete theory of cultural fields is expected to be more creative by acknowledging the possibility of multiple and intersecting and competing styles (Hebdige, 1979).

It should be known that the criticisms are not new and have been made by Certeau (1984) and Calhoun et al. (1993). However, as Mohr insisted, Bourdieu's own habitus led him to think linearly in the analysis of data rather than in more relational thinking, Therefore, Mohr (2013:112) suggests that Bourdieu's field measurement model be treated with different spatial logic in a non-linear analysis framework. To this end, he applies to Kurt Lewin, the social psychologist who first used the concept of space.

As we know, Kurt Lewin worked in the Child Welfare Research Center at Iowa University in the US after leaving Nazi Germany in 1933. He is one of the first scientists to develop a model of the topology of social spaces. Topology is a branch of mathematics as it is known, examining the unchanging properties of geometric shapes or three-dimensional objects. Kurt Lewin was influenced by Gestaltian views and Cassirer and used the concept of field space in Theoretical Physics, albeit slightly different in his work on social cognition. Lewin benefited from Einstein's discussion of field space, even as he has examined totality of coexisting facts within each other's interdependence. It is also necessary to underline the similarity between Kurt Lewin's "life space" concept and Norbert Elias's "survival unit".

In Lewin's model, there are no relationships or metric measurements in a straight-line dimension such as Bourdieu's. Lewin sees the habitat as the sum of the various "regions" in which each of the relevant elements of the individual's experiences are represented. The meaning of each region is defined by its location as well as by other regions in the living space. In this model, the individuals are represented dimensionless in the field as "point-region". On the other hand, they are also influenced positively or negatively by the objects in the spatial subregions (Allport, 1955:155)).

On the other hand, it should be noted that Lewin developed it by finding the topology model to be inadequate, and that he now called it a "hodoological" approach. According to Lewin, a more pure relational topological framework is needed to show complex dynamics in space. Lewin (1951:151) concludes that the resulting amalgam is a "hodological space". According to him, 
this space idea allows us to speak mathematically precise manner the changes of equality and differences of direction and distances, which are not easily seen in social psyhological field. According to Mohr (2013:115), Bourdieu was influenced by Lewinas one of his most important followers. However, since he is not a student of Lewin, he has embraced his model and preferred to consciously use his own formal scientific linear-dimensional method. Bourdieu did not use Lewin's concept of "hodological space" in field measurements. According to Mohr (2013:115), there's nothing to be surprised about. Because the hodological space was an anachronistic and clumsy analysis tool in terms of its use, and so others have developed a much easier to implement spatial measurement style by ignoring it. In the modern social network analysis, Lewin'shodological space has been transformed by new instituanalistsand the analysis of "organizational field" has begun (Mohr, 2008).

Mohr (2013), on the other hand, thinks that relationality, duality and topology can be used together in the field space measurement. The important thing for him is not technology but habitus. The tools we use in our analyzes are not the issue, whether they are multidimentional scaling analysis or "correspondancy analysis". There are also similarities between Bourdieu's analysis of corresponadancy and regression analysis commonly used in America, or they are not very different from each other. The important area is how the research problem is put forward and the possibilities of using the data.

Mohr(2013:127) stated that although Bourdieu was not an substancialist, he did not fully attain the relational approach in his analyzes, and that he went beyond essence, but was unable to fully relate to it. On the other hand, it is important for Mohr(2013:127) to point out that many mathematical function analyzes are extremely essentialist and that a new relational rationale is beginning to be developed in the sciences.

The importance of Bourdieu during our workshops with examples of applied relational sociological research has been emphasized many times. However, it should be noted that we did not conduct a Bourdieu-based research directly based on criticism and time limitations summarized in this subsection.

\section{WINDS FROM EUROPE II : N.ELIAS AND PROCESS BASED SOCIOLOGY}

One of the most important aspects of N. Elias, whose works are increasingly more influential in contemporary theorists over the last years, is the determinations of violence and democracy. In his most known "The CivizingProcess" (1939), Elias tried to show that there was an inversely proportional relationship between civilization and violence. According to him, civilization is democratized by the fact that there is no longer any need for violence in social relations and tolerates plurality. Elias, who thinks that civilization, will civilize if the monopoly of physical violence is taken away from the society and transferred to the state.It is not a prophecy to say that if Elias wasin the globalizing world, he would think that the civilization process would be interrupted almost everywhere at different rates, especially in the face of physical abuse.

If "survival units" is the starting point of relational sociology (Kaspersen and Gabriel, 2013: 51), then it is inevitable to admit that Elias is one of the milestones of relational sociology. Because Elias prefers to use the concepts of "survival units" as "figurations", which rejects the duality of structure and individual rather than the usual sociological concepts such as structure, individual and society, and describes them as inseparable parts and "subsections " of the whole. Thus, it attracts attention and is incomprehensible at first sight. But to put it briefly, survival units are the units that represent the highest level of integration with a social life at a certain time, carrying both autonomy and independence, or both aggression and defensive characteristics. These units can be from the family, the company or a small rural unit to the 
nation state. Also, Elias' methodological relationalism is very important, instead of single individuals, to transfer analysis units into human relations within groups and then to look at human relations within survival units (Kaspersen and Gabriel, 2013: 58).

Elias (1978) described the empirical study without theory as a travel without quidance and stated that work without empirical basis would remain dogmatic. Nonetheless, his work, known as figurative or procedural sociology, has been methodically criticized. At the beginning of these criticisms, it seems that he did not sufficiently explained and applyed the methodological principles in his work called "Civilization Process". Schröter (1997), on the other hand, argues that Elias did not engage in studies with majörtheory and practice integrity between 1940 and 1960, except for some minor efforts (cted in Baur and Ernst, 2011:118). In the following years, however, Elias succeeds in reaching beyond his famous work called the "Civilization Process", which is limited to the examination of the literature on the rules of etiquette, by carrying out studies that demonstrate the theory and empirical practice of completeness. In addition, in his following studies such as "Established and Outsiders" (1965); "Concept of Everyday Life" (1978); "What is Sociology?" (1970; 1978) and finally "Towards a Theory of Social Preocess" (1977) he shares his thoughts about the method briefly. In fact, Elias is not the only one who does not write about the method.Baur and Ernst (2011), like Kaspersen and Gabriel (2013), indicate that they are the ones who show them in their work, rather than writing the method as they did by K. Marx and M. Weber. At the beginning of the various reasons for this, the traditional method in Germany in the period they lived is to be "historical document analysis" including official statistics. Such understanding of methods based on document analysis lasted until the Second World War, and as a result of contact with the US, quantitative and qualitative analysis techniques of data gathering and empirical analysis began to develop in the field.

Elias is clearly critical of attending only quantitative surveys by going to the field. For him it is not possible to understand the social process, with surveys made by applying the assumptions about causality in natural sciences and physical measurements, mechanical model-based explanations and controversial generalizations.

Baur and Ernst (2011) examines what Elias thinks about the methodology and examines them first by taking as his example the works of "The Civilizing Process" (1939), "Court Society (1969)" and "Established and Outsiders" ( 1965). According to them, Elias is generally known as sociologist and theorist. Although he never saw himself as a methodologist, and even some of his practices seem to be outdated today, Elias has very clear methodological principles that are consistent with his figurative or process sociology.

According to Elias, sociology is an open-ended project. That is why it is possible to establish a connection between his methodology and current developments such as Mixed Method Research (MMR), grounded theory, ethnographic research, multi-level analysis, social-network analysis, cluster analysis, longitudinal and historical research. There are strong similarities between the process-produced data discussions and his methodological applications. So it would be a good start to make some comparisons to show Elias' methodological understanding:

Discussions of involvement and detachment: It is worth remembering that, firstly, positivists suggest that events exist outside us (eg, E.Durkheim) or that the subjectivity distorts the facts. Elias rejects this kind of a static subject-object relation by finding it totally impracticable. Because, in the process of gainining knowledge, as the knowledge changes, the subject itself changes as well, and even more information is gained by changing humanity for 
generations. In this context, Elias exhibits his "interpretative stance" like the previous German sociologist M. Weber. This posture is expressed by Elias' terminology as envolvement / involved subjectivity and against as a detachment without touching it.

Elias identifies them by making three types of subjectivity. These are classified as "versthen", "partiality" and "perspectivity" respectively (Baur, 2008, Baur and Ernst, 2011: 120)

A) Verstehen: According to Elias, in general, interpretation is essential for the understanding of the data and in particular human action. Therefore, such subjectivity is important in social science research. Today, Fetterman (1998) and other thinkers (Atkinsan and Hammersley, 2006) call it an "insider perspective".

B) Partiality: Sometimes researchers can interpret the data incorrectly or incorrectly because of the values they possess. This kind of subjectivity can destroy the research. For this reason, it is absolutely necessary to avoid such speculation at any cost. Elias is particularly sensitive in this regard. He categorically rejects the theory of action and system theory because of their ideological content. According to him, thoughts based on system theory can only be applied in a very limited way or not at all. For him, Marxists also pay the price of being "politically partisanship" (Elias, 1983). If we are to establish a link between Elias and Weber here, it can be recalled that, according to Weber, it is possible to make objective science, despite the subjective preferences. Thus, Weber argued that, starting from the selection of the research problem and the appropriate theoretical framework, the researcher was able to be objective by putting a distance between himself and the research topic, although he acted with subjective preferences (Weber, 1946). Elias also treats objectivity like Weber at the level of a problem researcher. However, the situation and the context can not be ignored in the discussions of subjectivity and objectivity. Because researchers are also a part of the society examined.

C) Perspektivity: Sometimes subjectivity is a prerequisite for understanding reality. This is because it is necessary for social science research to formulate problem and research questions to be associated with a certain theoretical stance, and then to select appropriate techniques to find answers to questions. From an ethnographic point of view it should be said that it is called "outsider-perspective".

Indeed, the tension between these three forms of subjectivity-objectivity reminds Habermas (1972) of the notion that the "unearthing" of interests may be encountered when information is gathered in the research. Elias agrees that social researchers are always a part of a figurations and social process. According to him, over time, our minds or ways of thinking become part of them with larger patterns as a result of experiences we experience, but often people are not aware of them. Social researchers choose a theoretical perspective for themselves to get rid of this partiality or dilemma. The aim is to be able to expand its own parts, to open it. To achieve this and to understand the social process, researchers must have an outsider- perspective in their analysis and reframing as much as possible the effects of the wider community on the periphery. On the other hand, however, they should not neglect to have an insider knowledege, ie subjective involvement, for the interpretive verstehen.

According to Elias, factual questions often carry political content. So they are rarely separated from political questions and remain detached. In other words, in reality, "interpretation" and "partiality" are intertwined. Nevertheless, Elias is concerned with the tense balance between commitment to the object of research and the detached analysis. According to Elias, although it is not possible to completely defeat the subjectivity, it is the researcher's responsibility to clarify partiality and perspectivity. 
According to Baur and Ernst (2011), it may be a criterion for a researcher to explain the reasons for choosing the theoretical framework that will guide the empirical research to reduce partiality. According to the interpretive approach; In social research, theories and data in which theory is constructed are closely linked. It is also impossible to collect and interpret data without theoretical focus. Without the conceptual framework of how data and theory connect together in the same way, the reliability of research can not be assessed. Elias also critically examines the division of the "theoretical" and "empirical" work.He believes that this tendency prevents production of larger-scale theories that will allow us to establish the necessary relationship between sociological practices and sociological theory.

Unlike other sociologists, Elias defends the unity of theory and practice. In doing so, rather than establishing ideal types (Weber) and statically examining the current situation, it is about making "dynamic" and "process-based sociology" based on real figures. As a matter of fact, this methodology has also been shown in his work "Establihed and the Outsiders" (1965) and also in the Court Society (1969), which he and Scotson have made. All this is in consistency with the idea that "sociological theory must be built to guide empirical work".

Elias's work has information on how to establish linkage between theory and empirical work. Indeed, according to Lindemann (2008), it is possible to distinguish between three types of theories with different levels of abstraction (social theory, middle -range theory and theory of societies thereby clarifying Elias's ideas. (Cited in Baur and Ernst, 2011: 122-123) :

A) Social Theories: Such theories seek answers following questions: "What is society"; "What are the central concepts in the analysis?"; "What do social reality look like and what kinds of considerations can we understand this reality?" In this context, the name of Elias' social theory is Process-oriented Figurative Sociology. As Baur and Ernst (2011) point out, social theory is prerequistite in seeking answers to questions about which way the researcher will gather data. Indeed, the symbolic interaction implies that the researcher will need qualitative data at the individual level, while structural functionalism implies at the outset that it is necessary to collect quantitative data at the macro level in the research.

B) (Middle range theories): Medium-length theories emerge when there is a certain thematic area, a historical period and concentration on a geographical area. In other words, the social process in this model is handled entirely within the context of a certain socio-historical process. It should be remembered here that the model is a pre-theory, a stage prior to reaching the set. Here, as in Elias's work "Grounded Theory" (Strauss and Corbin, 1990), analysis and synthesis are a matter of creating a medium-sized theory, and also testing this theory, by alterations between inductive, deductive procedures.For this purpose, in the "Court Society" (17th century) heanalyzes how Louis 14 in France uses the power he possesses in a certain figure to intelligently change society. Elieas and Scotson(1969) tell how the conflict between the newly established workers and those who have settled in the region despite the fact that they are from the same class in the "British Midlands". Describes in detail how the first inhabitants of the town struggled not to lose their monopoly in their working life by stigmatizing and excluding new comers.

C) Theory of Societies: The theory, as Elias (1939: 2000) did in his Civilizing Process, a wider picture emerged in an effort to integrate the results of many works. In other words, such a theory is built on middle- range theories, but with a higher level of abstraction from them. The main purpose here is to synthesise isolated findings to develop a "Theory of Increasing Differentiation" that will reveal the whole of planned and unplanned social processes, integration and functional differentiation. In fact, it can be said that this effort overlaps with 
Bourdieu's (1976) view of his book "La Distinction". In addition, this approach can be linked with the "Standpoint Theory", which has become increasingly popular in recent years. Because "Standpoint Theory" come close to relativistic sociology by rejecting dichotomies. In particular, the Feminist Standpoint Theory (Ramazanoglu and Holland, 2002) points out that by rejecting the male-female dichotomy, in other words, the idea that there is a homogenous male or female category is incomplete and inadequate, suggesting that there are different men / women.

Elias and process-oriented / produced methodology: Elias is known as "figurative sociology" in the first years of his work, but later he started to say "process sociology" by making terminology changes. It should not be surprising to see that his process-oriented methodology actually consists of a three-step process (in the form of reconstruction of macro, micro and sociogenesis) (Baur and Ernst, 2011: 123-124):

a) Reconstructing the macro-level: Here we are talking about the social structure and rules of figuration. Elias starts by defining a figuration. According to him, figuration is a social structure consisting of a series of individuals connected by a sequence of positions, norms and values. (Elias,1986). Figuration is a framework for organizing and directing their behaviors and communication for a group or individual action. Figurations vary according to the level of formalization and informatization as a means of meeting the social and physical needs of the individual. Within a figuration, there are differences in the accessibility of certain types of people or groups to such figuration status. Therefore, it is necessary to mention the difficulties that each individual has in a figuration as much as certain options depending on their status. For example, according to Elias (1969), there are rules in the French courtsociety that determine who is king and who is farmer. In addition, a king has an entirely different life chances. According to this figurative view, individuals are in tension and conflict. It would not be wrong to say here that Elias can be evaluated in a conflicting approach like Bourdieu. According to Elias, the first task of figurative sociology is therefore to reconstruct the structure and rules of the figuration at macro level. Thus, it will be possible to go back and see the process of appearance of the event.

The most important point to underline here is that while conducting a grounded theory study (Strauss and Corbin, 1990; 1998), it is also possible to use empirical observations as well as a "condtional matrix" which, based on documents of the socio-economic and historical background, ) Is also approved by Elias. It is not wrong to say that Elias once again showed the depth value of his method understanding that he had put forward this before the grounded theory debates..

b) Reconstructing micro-level: Here, it is a matter of placing the "individual" in figuration as having the power to change the figuration. According to Elias (1986), figuration creates an action framework that allows the individual to act in a less or more powerful way than the position in which the individual is. In fact, it is not always the case that a person with this ability always uses it. In other words, having the ability does not always mean the use of it. Elias also gives the example of the 14th Louis on micro level rebuilding. According to him, individuals can change their position in figuratione as well as change the figuration itself (vice versa). What is important for figurational sociology is how individuals are included or separated in this figuration, the relationships with the other members, the changes in their position throughout their lives and their causes, and finally how they change or change the figuration. This second stage gains importance with the emphasis of individual after the structure. In fact, it is possible to link C.W.Mills with this view. As a matter of fact, Mills (1969) points to the necessity of tide between the structure and the individual, dealing with the dominant human types and their biographies that stand out in certain social structures. On the 
other hand, C. W. Mills $(1953 ;$ 1954) is known to have acquanted with German sociology through Hans Gert, especially his work on Weber, which is the first author of Gerth, Character and Socail Structure. It is clear that N. Elias was influenced by M. Weber as a German himself. Indeed, it is possible to read the Civilizing Process as a "rationalization process" with the Weber terminology.

c) Reconstructing the sociogenesis of the figuration: According to Elias and his process sociology, both individuals and their figurations are constantly changing and interacting with each other. According to Elias (1983), since the society is constantly changing, there is no use of abstract theories such as system theory and structural functionalism. Instead, in terms of figuration analysis, sociological studies must always be process-oriented, focusing on explaining social processes.

According to Elias only to be interested in "today" limits sociology and therefore he closeshis doors to postmodern views that are more interested in now / today and here . Elias (2006) finds that many sociological studies are merely an empirical study that is not tied to the past carries important weakness. According to him, sociologists should look back not only because they are interesting but also because they will give them greater awareness of contemporary problems. Therefore, diachronic studies should be made as well as synchronic studies and a bridge between the past and the future should be established. It can be said that Elias' goals, which aim to develop medium-sized social theories by making change-oriented dynamic and process-based sociology instead of static sociology.

When one examines how Elias analyzes data in process-oriented methodological studies, it appears that he possesses qualities that can be described as a qualitative research expert or a sociologist of historical studies (Baur and Ernst, 2011: 126). On the other hand, it can be said that instead of favoring any of the qualitative and quantitative researches, he is the forerunner of today's "mixed design" research approach with both advocating views.

Elias has also carefully clarified which research methods would be compatible for which level of research (Baur and Ernst, 2011: 126):

a) Data and methods for reconstructing the macro-level:According to him for process based sociology the first important task is to handle figurations as a whole at the macro level. Elias uses two types of data to reach this objective:

These include maps, landscape paintings, building plans, as did Palmer from the US / Chicago School, sociologist Bourdieu from France and historian Braudel. Because they can show us hidden rules and social structures. For example, home plans give clues to everyday life practices. As a matter of fact, Elias observed that the bedrooms and living areas of the arictocratic couples were separate in the "Court Society" research. Here, Elias reveals changes in the civilizing process by comparing the palace and other building plans, historical documents, and books on etiquette. Collected data from a few sources in the form of triangulates, tells us that there are significant changes in everyday life. For example couples had separate bedrooms up to modern times. In modern times couples started to share same bedrooms. In fact, Elias, as he did in the work of the "Court Society", also pioneered "spatial methods" by studying the changes in the use of space. As a matter of fact, Bourdieu (1978) continued this tradition with "topological" analysis. As emphasized by Wallerstein (1999), not only time but also spatial dimension involvement in analysis is of great importance in social change analysis. As a matter of fact, Bechelard (1964) also influenced relational sociology with works emphasizing the importance of space in everyday life. 
Secondly, Elias is against the "standardized data," that is, the excessive collection of data by closed-ended questions frequently found in questionnaires and interviews. One of the factors that cause him to think like this is that he finds a single source of data insufficient. Secondly, standard data need to be interpreted because they bear the risk of "measurement errors". Nevertheless, there is a danger that researchers may find this data objective. That is why Elias keeps his process sociology separate from longitudinal follow-up studies. So Elias keeps his process sociology separate from follow-up studies. Another way of saying that his methodology is not concerned with the categories that natural science needs to do for many times. Finally, since standard data collection tools in 1950 and 1960 have not been over-developed yet, such standard data are already quite limited in those times. Despite all these critical views, Elias is known to conduct surveys to obtain standardized data. At the beginning of these, besides the aforementioned "Established and Outsiders (1965)," "Techinization and Civilization, 1995" and" Young Workers Project "(2006). In his "Techinization and Cilization" study, Elias used transportation statistics from different countries as an indicator of the improvements in selfregulating social standards. On the other hand, because he was skeptical about overusing statistics, he conducted interviews with 900 young people in his work called Young Workers in Leicester, England. Established and Outsiders (1965)he used mixed patterns. In this work he did with Scotson, he used survey data along with document analysis and crime statistics.

b) Data and methods fort reconstructing the micro-level: According to Elias, it is also important that individuals investigate how they perceive the figuration, how they relate to each other, their effects on figuration as well as changes they undergo during their lives. In obtaining such data, Elias uses the information he collects with more open-ended questions.

Elias uses documents such as letters and autobiographies as historical sources, similar to the historians, while recreating the activity of the individual in the past, as in the Court Society (1969). In his Civilization Process (1939: 2000), he compares the rules of the kitchen table, the bedroom, and the bathroom, starting from the Middle Ages to the daytime etiquette books on the basis of husband-wife and parent-child relationships. In his work "Mozart Genious' Sociology" (2000) he collects social history documents for that period for a very long time. Elias died before the book was published by the editör. In this study, through Mozart's personality Elias tried to show that not only the economic but cultural aspects of the struggles between the aristocracy and the newly strengthening bourgeois class were very important. So much so that Mozart did not ring his works in the palaces because he was not flattered, he fell into poverty because he did not obey the aristocracy. It is the bourgeoisie that has been proctecting of his works after his death. Here, Elias restructured at the macro and micro level, aiming to describe both economic and cultural struggle in the time and palace (space) that Mozart lived. His analysis also included the depression of Mozart's because of exclusion by both the palace and his wife. Thus, the work becomes valuable as an exceptional example of the interaction between the structure and the individual and the culture together and as a process.

Elias also uses ethnographic investigations to analyze the current actions of individuals. For example, the work "Established and Outsiders" follows the traces of the Chicago school of America and the famous Marienthal work (Jahado et al., 1933; 2002). As mentioned earlier, Elias and Scotson used historical documents, crime statistics and surveys of gathering together in the form of triangulates, while examining the historical development of this industrial town. It is also known that they also performed "participatory observation" in this study. These observations were made during interviews conducted at the homes of the inhabitants or at workplaces. Thus, researchers who conducted space analysis have shown that families are mother-centered, and that the duration of the neighborhood is an independent figuration of neighbors gossiping about each other's blames, accusations and praises. In fact, the study by 
MübeccelKıray of Ereğli Heavy Industrial Village (1964) is also an example of this kind of work. As a matter of fact, Kiray has developed the concept of "buffer mechanism" and has described the tools developed by the society as a "mechanism" for rapid change. Kiray, as an example of buffer mechanisms, has described the grandmother's looking after children in the absence of creches in the town and the borrowing from the lenders because the citizens can notfulfill the conditions of obtaining credit. In this context, the historical importance of this study should be underlined.

c) Data and methods for reconstructing sociogenesis: After appropriate data and methods for macro and micro restructuring in a given time period, the method suitable for thesosyogenesis figuration sequence has been followed. In fact, process-oriented analysis is most appropriate for figural analysis. Because the formation, change and ending of this figuration should be analyzed as a process. In the plane of thought, this means the restructuring of the relationship between figuration and individual at several points in time .

Elias thinks that other modern sociologists are interested in making research-elicited data, but they neglect the collecting of "process-produced data". Contrary to them, Elias has focused all attention on generating information based on process. According to Elias, data on events that have occurred in the medium-term or near-term can easily be obtained through interviews. However, if we do research retrospectively over longer spans, the information source may be dead, as people's memories may mislead them. In such cases, we need to reconstruct the events we have investigated by moving from written documents. So when we do longer-term research like sociogenesis, we need to know that different data types are needed. Anything else that comes from people can be a source of information for us. Elias, for example, used the books of etiquette as a source of information in the sociogenesis study called the Civilizing Process, by redefining changes in people's lifestyles.

Elias is always insistent on using theory as a guide in his empirical work. In this context, according to Baur and Ernst (2011: 132):

A) Divide the analysis period: Elias analyzes the civilization process by dividing the period from the 17 th century to the present day into sub-circuits.

B) To document each period: Elias selects documents showing the lifestyles of each period separately. While researching the process of civilization, he often examines best seller books of etiquette rules. This is because it is assumeed that these rules are applied more extensively, depending on the most demanded. It also suggests that the most used or requested documents of the period should be centered by the researcher when he is reconstructing the period.

C) Making periodic comparisons: Elias makes comparisons over time to keep track of the changes in the figurative variation. In this way, it is possible to display in which period the phenomenon that has been studied has emerged, developed or disappeared. For example, in the Middle Ages, when Elias adopted it as the first period, the relieve of one within everyone is a widespread practice, and no one feels uncomfortable with it. Later, as the power struggles between the people increase, it is written in the etiquette books that it is inappropriate and bad behavior to defecate among the others. Elias states that in the socialization process that he has called the third period, children learn to control their bodies by taking toilet training and that is subject no longer included in the etiquette books.

As Baur and Ernst (2011) emphasize, Elias collects and analyzes information in a very systematic way in his research, although he does not write a method book. His comparative purposeful cross-reading and process-based figurative method by providing the opportunity to 
see the hidden and unintended consequences of human action together is extremely important. As a matter of fact, Kuzmics (2009), one of the followers of this method, showed how Elias' theoretical concepts could be researchable by making use of diaries, letters and literature. In addition, one can look at how Ernst (2009) works on how content analysis can be used to investigate long-running processes and how to interpret them. There are also studies in Turkey based on content analysis of various problems using newspapers, magazines and even textbooks. However, it is clear that more attention and information are needed to make them more systematically comparative and process-oriented, as Elias did rigoriously.

As a result, Elias uses the concept of "figuration" because of the inadequacy of existing concepts of sociology in describing interdependence between individuals and society. Here, it is worth respecting to overcome the deficiencies of modernity by staying in modernity, and most importantly, to develop alternative concepts to individual-community dichotomy. On the other hand, it is also worth mentioning that the Civilizing Process (1939), which was invaluable and absurd in Germany in the first years of writing, began to be shown as an example of relational sociological studies after being translated into English in 1969 and then being important in understanding everyday life.

\section{WINDS FROM EUROPE III. : O.KIVINEN AND T. PIIROINEN AND NICH CONSTRUCTION}

Indeed, Kivinen and Piiroinen(2013), who made methodological explanations on relationality through the "niches" which can be defined as the smallest social unit argue that this approach is "sociologizingphilosopy" with a "pragmatist" attitude. They are entirely opposed to "philosophizing sociology" in ontological and metaphysical premises. According to them, efforts to understand all knowledge including philosophical ontology are social affair. Kivinen and Piiroinen(2004; 2006;2007; 2013), have pointed out that claims to provide ontological foundations to social sciences, coupled with "realist" attitude philosophy, are no longer sufficient. Their point of departure is "evolutioniary niches" with Darwinian approach and "theory of pragmatist action" from Dewey. Their main purpose is to understand the "human transaction mechanisms" by placing them in context.

Here Pragmatism is not simply handled as utilitarianism, but an important source of information for problem solving. Being problem driven and its definition is the basis of all relational sociology. Indeed, Creswell (1997) sees the problem as being based on qualitative traditions.

Relational sociology approaches positivism from a critical perspective. However, because of its biology and Darwinian viewpoint, positivist traits are noteworthy. Because both writers find the ontological approach, which is based on metaphysics as "everything in the world is related to each other," it is simple and obsolete. Kivinen and Piiroinen want to have relationalism on a scientific basis, and thus describe by biologic analogies what it means in particular the methodolologicalrelationist stand point. It is observed here that the Dewey + Darvin $=$ relational sociology equation is simply confronted here.

According to Kivinen and Piiroinen(2006; 2013:84), it is necessary to mention that we are "problem-driven" at the beginning of a research with a Dewey (1938) approach. It is not scientific to try to say what the ultimate nature of the working subject is, since it requires a metaphysical conceptualization rather than a scientific attitude. It is important to aim at exploring a well-defined research problem in the context of a specific place, time and action. Therefore, it is necessary to be problem-driven rather than the theory driven to the ontological metaphysics at the beginning. This attitude removes the necessity to be guided by theory or to observe certain theories. Because the theoretical frameworks needed to solve the problem can 
be either from the field or from existing concepts. Here, the hypothetical deductive approach and positivism are criticized.

Kivinen and Pyroinen (2013) accept the principles of the Relational Sociology Manifesto, written by Mustafa Emirbayer (1997:281). According to them, the idea that social life is basically "static" and composed of "substances" is unacceptable. Rather, it is necessary to make sociology knowing that social life consists of dynamic, processual, and unfolding relations, and thus move away from metaphysical explanations (Emirbayer, 1997;282). Emirbayeralso states that relational ontology is by no means related to relational epistemology and methodology and does not need it either. However, it should be noted that there are differences among relational sociologists. Margaret Archer (1995), for example, suggests "analytical dualism", which criticised many anti-dualist relationalists (De Pelteau 2008). It should not be forgotten that anti-dualism is one of the most basic indicators of relational thinking.

Kivinen and Piiroinen (2013:85) embrace the same methodological relationalism that Dewey (1922; 1983) describes in Theory of Action. This means to reject all dualities such as subjectobject, mind-body, individual-society, theory-practice, conciousness - world in our analyzes in our analyzes.They reject the view based on the mind-body distinction as if the mind comes before the body or is independent. They acknowledge that the organism is constantly interacting with its environment and that it has become habits. Organic life is basically the process of activity that involves an environment. This transaction goes beyond the spatial limits organizm. Therefore, organism-environment transactions can best be understood relationally. In such an approach, the researcher does not need to ask questions such as what the environment really is, or whether the organism is independent from enviroment or not. There is also no need for philosophical dualisms to understand the processes between the organism and the environment. Because, according to Dewey (1922), it is a serious mistake to consider the organism and its environment from the beginning separately and to regard the interaction as a third party. In fact, there is an independent world no one can deny. But it means that the world enters into life-functions as an environment, directly or indirectly. Having such an understanding is undoubtedly influential on our thinking about what knowledge and inquiry and research are. Kivinen and Piiroinen here want to emphasize that they are separated from philosophical ontology and make scientific explanations. It should not be forgotten that idealistic thought does not make a distinction between subject and object metaphysically. Subject-object separation, that is, dichotomies is the basis of positivist philosophy. Remember the concept of God in the "geist" / final analysis that Hegel puts on the basis of everything. Thus, it can be said that Kivinen and Piiroinendo not fall into the trap of idealism by resorting to Darwin.

It is said that social mechanisms are important in social sciences, and even as a metaphor, they are Holy Grail of Jesus' last meal. But then, the concept of mechanism has largely been replaced by "laws" - or "nature laws" (Machemer et al., 2000). There are different opinions about what social mechanisms are without any doubt. However, when it is referred to as "mechanism" by methodological relationalists, it is understandable to explain the causes and effects that are effective on the research problem in question, and the tools that help us to foresee them (cited in Kivinenve Piiroinen,2013:86).

As indicated by Peter Hedström and Petri Ylikoski (2010), "mechanism schemes" show us how to make possible explanations of events depending on the effects of certain actions and relations. This means approaching them through the effects they make to the mechanism. On the other hand, the point of attention is that they actually defend structural individualism. In other words, they are all social phenomena, structures and change that can be explained in 
terms of individuals, their actions and their relations with each other. It is clear that such an approach carries the risk that social life is psychologized in the form of individuals' desires, beliefs and opportunities. Therefore, it is necessary to see that actions occur in society, during transactions that continue with the environment. In other words, it is more suitable for sociology to show that actions take place as a result of transactions with the environment, rather than emphasizing the individual on the psychological dimension (Kivinen and Piiroinen,2013:86)

Kivinen and Piiroinen (2013) also oppose the idea of "micro-foundations". They reject the idea of micro-foundations, which imply that social life is handled in levels. They are particularly opposed to the idea that some levels should be reduced to others. Such a view is that the researcher will not be able to have the evolutionary framework to understand all the relevant actions and events. These statements can be said to be the clearest indication that they have the Darwinian view of evolution.

According to Kivinen and Pyroinen (2013:87), it is possible to construct very different mechanism projects or schemes for various scientific purposes. While a case study is conducted to solve a specific problem, may be more appropriate, while others may be rejected. They think more or less Darwin's idea of "evolution" should be accepted in order to be able to choose the most efficient mechanisms projects in social sciences. According to them, human evolution occurs especially in the niches / smallest units of social action. Darwin's idea of evolution implies that research should be done historically / diachronicly rather than synchronicly to solve social problems. It is clear that Kivinen and Piiroinen (2013) think like Elias in this regard. It is not possible to understand and explain social problems from the latest situations. For example, identity, security and conflicts in Turkey can not be resolved without knowing their historical background.

Kivinen and Piiroinen (2013:87) especially avoid sociology to reduce psychology unnecessarily. For this reason, they are obviously focused on the evolutionist niches of social action when examining the evolution of human mechanisms.

Kvinen and Piiroinen (2013) point out that the concept of "niche construction" taken from evolutionary biology has been discussed quite a bit in recent years and is basically pointing to two things. First, organisms and organism communities / populations evolve more or less successfully within their ecological niche. Evolution happens throughout generations. These niches have the ability to determine which features or habits of action in evolution are more or less useful in coping with the environment. The second characteristic is that the functioning mechanisms of the niches as living organisms, which are sometimes skipped by the traditional or standard Darwinian evolutionary view, have the capacity to continuously change both themselves and their local environment. In other words, not only the living organisms but also the environment changes over time. This is because of the selective pressure applied by the niches on the environment (Laland and Streleny, 2006;Kivinen and Piiroinen,2012).

Kivinen and Piiroinen (2013;87) give many examples about the niche construction by the living organisms. For example, when spiders are netting, beavers, known as nature's architects, cut large trees and make barrages. Many of them, especially ants, collect and store food. Even plants that are not capable of movement can have an impact on the environment. For example, while trees change humidity in the air, some plants can have an impact on the fertility of the soil. Similarly, the community; culture, language use, human life in technology and institutions, ideas, habits offer a rich source for different kind of niches. 
On the other hand, according to evolutionist thinkers such as Kivinen and Piiroinen, an evolutionist explanation for finding the most appropriate and most relevant causal mechanisms should pay attention to how the actions of the organisms change and how the organism changes the environment (habitat). That is why an evolutionist view is needed to understand social action and its mechanisms. Such an approach requires examining the historical development of the problem studied as far back as its competence.

What the Kivinen and Piiroinenwant to conclude is, like Elias, clearly showing the link between "methodological relationalism" and the pragmatist approach to action and evolutionary niche construction (Kivinen and Piiroinen, 2012:88). On the other hand, they also point out that other thinkers, especially Dewey (1938), had this idea long ago, although they were not explicitly included as niche constructions.

According to Kivinen and Piiroinen (2013:89), there are those who, like Durham (1991), think that both human beings and their cultural niches are in the process of constant evolution within coevolution. On the other hand, there are a number of thinkers but not to much, (Deacon,1997; Donald, 2011; KivinenvePiiroinen, 2012; 2013) they understood that , language, consciousness, different forms of social life, social institutions, and a whole "behavioral modernity," meaning that human-specific traits that distinguish us from all other creatures have emerged in this evolutionary process. According to them, it is possible to understand all human life by referring to the evolutionary process. Darwin's "statistical selection processes and American pragmatism have revolutionized thought in the late 19th century (Brandom, 2004). Because the habits that do not work in the elimination process disappear from the social life and thus slightly changes occur in the niches. Here, the link between Dewey's "instrumental" view of what is useful and real, and the idea of evolution is quite obvious.

All that has been said so far is the kind of explanation that will help us to understand relational sociology. Because, from the outset, the dualistic viewpoints have been ignored and tried to be based on a holistic viewpoint. In other words, human action in social niches is understood as a continuous, dynamic and ongoing process of process between the niches of social life and their human actors. Thus, relational thinking based on niche construction is exactly the opposite of deep dualisms and dichotomous thinking.

Kivinen and Piiroinen (2013) rightly believe that some other thinkers', for example Randall Collins and Pierre Bourdieu's concepts, can also be re-read in the context of niche construction. In their view, concepts such as Randall Collins (1998:90) and his "interaction ritual chains" and "emotional energy" and "limited attention space" are concepts developed to show social niches in the dynamic world of the intellectual community. According to them, Bourdieu's concepts of "habitus", "fields" and "capital" are also examples of paradigm types. Because people in the niches in social life, in order to be able to adapt; Have the capacity to both uphold and change these standards, frameworks and social habitats while at the same time succeeding or failing according to various standards. In summary, they accept the individual as active and powerful on the periphery, rather than being passive.

On the other hand authors insist on the importance of language. Because the language is a tool that enables us to do anything that is person-specific. According to them, there are very important lessons that the relationalist evolutionist perspective will teach us about social investigation and methodology. To understand this clearly, it is necessary to admit that the language has evolved. 
As relationalists emphasize, human life can best be understood when it is enframed by social evolution. This means, in fact, to look at the continuous and reciprocal construction process of people's social action niches. On the other hand, other social scientists, like relationalists, have a methodological advantage in raising their awareness.As mentioned earlier, the evolutionist approach requires some retrospect to look back at the events in the chain of cause-effect relationships, to get a better understanding of the subject matter studied. This perspective is not easy to be understood by realists who are stuck on the subject-object dualism ontologically. The best example of this is Noam Chomsky (2002), fed from the Descartesian tradition, and his obsolete thoughts that deny communicative action. According to relationalists, as the distinctive and original character of man, the mechanisms of evolution of language and language need to be understood. In other words, it is necessary to examine the evolution of social action niches. As Deacon (1997) pointed out, there has never been a Big Bang on language. Rather, it has become the language of the present day as a result of the evolution of events that interact with each other in chains and follow each other for thousands or even millions of years. Another important point that needs to be mentioned here is that evolutionist brain science or psychology is not needed to understand language evolution. Instead, evolutionist sociology is needed to hold the niches of social life in the foreground. The main reason for this is that the choices in language evolution are made by groups, not individuals. (Bickerton, 2009, Deacon, 1997, Kivinen and Piiroinen, 2012, 2013:91). Because not individuals but certain groups begin to use the most appropriate language or protolanguage when they enter the struggle for life with the environment. For example, in Africa, when the rain forests become desert due to warming, first people (hominids) run to escape, they developed hand skills to use tools and needed communication to build better coordination and developed languages as tools.

The idea of building a niche allows us to understand why and how the language has evolved since from the beginning. Understanding the construction of the language is an extremely important tool in understanding the construction of many other cognitive and other niches. That is why it has been suggested by Dewey $(1925 ; 1988)$ that the language is the "tool of tools" that makes a difference between man and animal. Language connects us in the community as a communicative action as much as a tool for thinking. Likewise, in the DeweyWittgenstein-Rorty tradition, words are regarded as deeds, in which people describe relations with the environment, and relational networks in a kind of organism-environment process. Language today helps us to cope with our environment as never before. As noted by Gargani (2011), language is our personal and community history in the symbolic world, who and what we are. When we tell stories about our beliefs, it connect us with each other as intermediaries. In this way, we redefine ourselves and other things in the world and continue to reinterpret them. This is important, though not as a reflection of the world in a very transperant way, as realists think.

As is known, in a place where words have meaning, only people symbolically form "communication communities". In addition, language not only expresses thought, it also informs people about what conscience is. On the other hand, according to Dewey (1925), these communities provide for the formation of human consciousness and mental life.

According to Kivinen and Piiroinen (2013:92), knowledge, conscious thought, linguistics and other symbol systems are instruments that can not be sperated from each other in scientific investigations that overlook human life. The most important point here is that these tools provide us with the intentional stance of explaining what people want and what they believe. In short, knowing what language is (that is, knowing that the capacity of coordinating between groups and evolving) important for a better understanding of what social sciences and 
research are. It should be remembered historically that people do not have or have no habit of using symbol systems, although other creatures have the ability to solve the problems they face. Certainly, the ability of people to solve problems through language can be said to be higher than other living things.

Another very important point that should be addressed methodologically is that the language inevitably has a social nature. In other words, all of our consciousness and knowledge are closely connected to the social environment we live in, or to the niches as the smallest social unit. This shows us that the language is clearly relational. Because words get meaning by interrelating with each other in networks. Likewise, language differences in social life are always indicators of relevance. All of these are important explanations of the fact that linguistic and consequently human studies are relational. On the other hand, a relational methodological approach argues that social scientific knowledge is a relational tool in solving the problems of relational social action. All of these are important clues to a holistic view based on pragmatism for problem solving purposes.

According to Kivinen and Piarinen (2013:94-95), in social life, besides language, another important concept is the niche. Because the concept of niche is important in the development of middle range theory, where social space is very important as a group instead of an individual. The evolution of mankind or humanity has lasted thousands and even millions of years and has been in groups. The phenomena are also indicative of the importance of sociology in the sense of humanity and why sociology is needed. As much as the understanding of the importance of the linguistic niches of social life, "sociology of mind" has provided us with a sense of how dramatically the human consciousness has changed over the last 100 years, among other things. These changes can only be explained by the great changes in the way our habits work in social niches. In reality, it is the changing groups themselves. Social networks transcend time and space dimensions, and a large number of new and different group identities emerge in human brains. It is also clear that these new and different identities are not highly preferred by the individual. At the same time, last century with the internet and portable communication tools, even in the last 20-30 years, people have experienced a revolution in knowledge and thought. As a result, human consciousness has changed. Because of constant changes in organism-environment processes. Since it is known that the human brain has not changed much in the last 200,000 years, "how will this change in human consciousness be explained?" The answer to this question by Kivinen and Piiroinen (2013) is that a new kind of evolutionist sociology will explain changes in human consciousness. In other words, sociology will consider the niches that are very important to social groups in social life and will explain the individuals in this context.

\section{WINDS FROM UNITED STATES: H WHITE AND UNCERTAINTY STUDIES}

In our book writing project we have been trying to do relational sociology in the same way that one is practiced by the US (Harrsion White) and the other by Europe (Norbert Elias). For this reason, Harrison White's views, which give important clues to sociologists have been reviewed in detail trough the article published in collaboration with F. C. Godart and M. Thiemann, entitled "Turning Points and Possibilities: A Relational Approach to Different Forms of Uncertainty" (2013). Because in the mid-1990s, a New York-based relationship-network emerged among those interested in historical and cultural analysis, although they were working at different universities and in different fields. Among them is Harrison White who is interested in language evolution, working on identity and control has come to Columbia University and transforms the previous positivist science into a more interdisciplinary studies. 
Some thinkers engaged in relational sociology prefer to use the concept of "identity" in a more abstract and broad sense, rather than individual, person or subject. One of these is $\mathrm{H}$. White, an important name in relational sociology. After studying theoretical physics, he was a doctor of sociology at Princeton University in the USA. White is actually known for its structure of production markets and network / network analysis. "Identity and Control" (1992) is his most important work. He is interested in controlling identities through uncertainty through Game Theory. It is especially noteworthy that the examples of the examined articles are given from the market and the enterprises.

It is also worth remembering the links between Game Theory and Bourdieau's concept of "play / drama" (illisio) and Goffman's (1959) Dramaturgical Sociology. In fact, the study of uncertainties in modernity has an important place in relational sociology studies. Because, while analyzing the cultural factors as well as the structure and the individual, it is necessary to consider the changes and possibilities while reducing the determined areas. Bourdieu's "space of possibles" already point to these cultural differences. Hence Bourdieu's contribution to uncertainty studies is clear by the notion of "space of possibles"(Bourdieu,1993:176).

According to White (2008:137), "identities" are very important. Identities can be defined as"any source of action, any entity to which observers can attiribute meaning not explicable from biophycsical regularities. " On the other hand, identities can be of any level, area or scale, and are exposed by a constantly changing and uncertain environment. There is a need for work on how to ensure control because of the "footing" requirement that arises in case of uncertainty. It should also be known that there is a difference between risk and uncertainty. Because risks can be handled through insurance mechanisms, a full insurance for uncertainties can never be the case.

Risk, uncertainty and trust are in fact very closely related to each other. As Luhmann (2006) points out, trusting in uncertainty means actually taking risks. There is also a close relationship between trust and power. Because social life is actually power struggle. You need to take risks and rely on strength. Undoubtedly, communication is also a fundamental process in Luhmann, and so he has developed a theory of communication. In the course of relational sociology, the process of examination of the important process actually corresponds to the "communication process". Briefly, relational sociology is made by looking at structure, individual and culture interaction, in the communication process. On the other hand, the rich and varied possibilities provided by communication technologies today also have to be included in the analysis.

In fact, it is known that various institutions and regimes have emerged to support identities in chaotic settings (Corona and Godart, 2010). The role of sociology here is to examine the dynamics of social formation. This review will need to consider the evolution of meaning. The conceptual distinction in this regard is due to associates and observers in the social networks / networks. The distinction between "social networks " and "networks of meaning" is analytical. In other words, social networks and meanings are in fact indivisible and interwinning. The differentiation made here is to make analyzeshealthier and reliable (Godart and White, 2010).

According to White et al. (2011), among the participants who observe networks and meanings in the first and second levels or terms, there are two concepts in examining the aforementioned uncertainties: These concepts are "ambage" and "ambiguity". Ambage is uncertanity in social relations, ambiguity is uncertainty in meaning. On the other hand, there is a third uncertainty. This is called "contingency". In summary, there are three types of uncertainty (White et al., 2013:138-139). 
A) Ambage: uncertainty in relation

B) Ambiguity: The ambiguity of meaning

C) Contingency: Imitation is the case where random / probable variables are used. This uncertainty situation is external to the system.

Another important concept in terms of our topic is "turning points". Because "uncertainties" arise in "turning points" that allow to make strategy or game changes in identities according to increases or decreases in various forms such as ambage, ambiguities or unexpected situations.

Here, as Bourdieu (1993) expresses for each identity, a new turning point emerges as the "space of possibles" change. "Space of Possibles" refers to the cultural space. Contrary to Kant's universal values, cultural values indicate that they have changed from society to society. Remember that Bourdieu points out "distinctions" in class analysis. Because the taste of each class is different. The problem is not only economic differences, but cultural capital and social differences. For instance, social capital is the wealth and diversity of social networking.

In this context, the "social relationship" and the dynamics of meanings also encompass the strategies of identities seeking footing. It is especially important that in all occurrences, White and his colleagues (2013) describe it as "disciplines". In this theoretical framework, disciplines are the forefront for the regulatory duties. Because turning points always appear in the concrete conditions of disciplines. Strategies and games developed by idenditities provide sociologists with ways to measure uncertainties.

There are many studies on uncertainty (Beckman et al., 2004; Huault and Reinelli-Le Montagner, 2009). As mentioned earlier, White (1992, 2008) classifies them as three kinds of uncertanity faces: "ambage" in social relations, "ambiguity" in meaning, and "contingency"external to the system.

Ambage: This is the uncertainty that arises entirely within the framework of social relations. According to White (2008), the word originates as winding or indirect, or roundabout. In terms of relational sociology, it shows how social roles are performed and enforced. The Ambage also tells how social relations are created, how they are suspended, and how they are terminated. As pointed out by Goffman (1959), there are anticipations and promises for each role as well as avoidance of their fulfillment. Ambage is a concept used to describe situations in which expectations of a role are not fulfilled (cited in White et al., 2013:139)

White and his friends (2013:139) especiallexamine how the market works. The roles of the parties involved in the market, such as the current staff and the newcomers to the market, are clearly defined. Officers in charge are a guarantee of ensuring market order. The uncertainty here is about how the actors involved in the market are performed or practiced rather than what the role requirements are (Weick, 1979). Interpretation of how to perform or play the role has to do with strategy. Therefore, how to establish the bonds of social relations requires a perspective to be taken or terminated. For example, officers in a particular market may try to raise the market in price war. In Turkey, for example, politicians are always increasing tension in the electoral process.

For White and his colleagues (2013:139), the practice depends on the strategies of different actors. The regulatory authorities involved in this are also included. Officers in today's free markets are also obliged to provide infrastructure for monitoring changes in the bond price for new entrants to the market. In summary, for each identity, the "ambage" is the answer to the 
question: "Do the others fulfill the needs of their role, or are there any failures or limitations in meeting the role requirements?"

Ambiguity: According to White (2008;37; 2011:139), ambiguity is an uncertanity that appears entirely in "cultural context". This uncertainty is about the meanings as well as about the rules. Because the rules express the meaning of the environment. Ambiguity arises in the interpretation or meaning of which particular signals or markings belong to which rules. Ambiguity is not "ambage", forcing it to comply with rules. Communication is established in the marketplace with signals. Marks or signals are the most important source of both ambiguity and its reduction. For example, the meaning of the price drop in the telecommunications market is quite uncertain. Companies may also lower their prices to increase prices in other products, and there is now a decline in uncertainty. Because companies may want to reach new consumers by lowering prices with a new strategy. The ambiguity for each identity can be summed up by the question: What do the others want when they are in action or talking?

Ambage and ambiguity are two dynamics that progress one after the other. For example, when a new identity is included in the social network, it will try to understand the current environment. This will cause discomfort in the role expectations of those already in the relationship network.

Contingency: According to White et al. (2013:140), the state of being unexpected or coincidental is related to the probability of survive at a certain level. These possibilities are observed by identities in other identities' of social networks.

Unexpected uncertainties arise from external influences on the social network. However, ambage and ambiguity may also be effective in the event of unexpected or uncertainty arising from chance. For example, as in the case of telecommunications, what is the chance of success for new entrants to the market? Likelihoods for a newly organized market are compared with similar markets. These anticipations reveal the investment of each actor as a result of competition and cooperation with other actors. Standing or anticipated probabilities of life also affect expectations about future relationships. In this context, "Game Theory" tell us about the traces of our expectations about the future (Dasgupta, 1988). Expected life possibilities can translate into an imbalance between them through significant influence on the reputation of the identities, by reducing the ambage(Dasgupta, 1988). For each identity, contingencies can be summed up by the question: "How can other identities still exist in the present situation? What are the situations in which they are absent or will they gain different status in future time? "In Turkey, for example, Syrian immigrants entering the market and working at lower wages will reduce the bargaining power of current domestic workers. Similar situations have been mentioned in Europe.In many countries governments ignore foreign or illegal workers.

"Turning points" arise when the change is effective on one of three different uncertainties. The turning points are actually understood as a result / output of the change in the space of possibles. The importance of change can not be determined apriori. In fact, the changes in uncertainty are at different levels and can be described as "unpredictability" and "irreversibility". Whilst unpredictability refers to the uncertainty between successive events or actions, irreversibility is the persistence of outputs (White et al., 2013:140). In fact, some changes are both more predictable and reversible than others. For example, a birthday celebration can be foreseen because it is predictable, but it can not be celebrated at the end of the day because it is irreverasble. The poker game is reversable and unpredictable. Routines can be both predictable and reversible. Similarly, it is known that historians describe historical processes by constructing events such as beginning, development and conclusion in a 
consecutive manner (Bearman et al., 1999). In the process of this casing, the authors agree that the meaning of the events is determined by the position of the events in the network as they follow each other. Incorporation or removal of some events is not always, but sometimes, changes the narrative and meaning of other events.

The space of posisibles is variable for different segments of society. For example, in Turkey, physicians have lost their prestige after the performance system and have become both worker and target of violence in health system. Foreign immigrants such as Surian refugees also put their lives at risk for freedom. The immigrants we see as relatives in the past are now strangers who we do not know where they will end up. But even in the short term, immigrants / refugees can begin to live humanely once the balances change in the Middle East.

Their robustness is as important as the unpredictability and irreversibility of events. In addition, White and colleagues argue that the final definitions can be made ex-post after the events have taken place. Although these factors provide useful conceptual frameworks for exante studies, uncertanities are always in question. For example, when competitive firms in the market, or others, perceive small changes in pricing strategies as a price war, nobody knows how this affects the market. In fact, as Abbott (2001) points out, the turning point does not always appear; but it has the potential to appear every second.

Gaming: Identities disciplining uncertainties: Unlike the determinations of neoclassical economists, identities do not try to maximize the abstract utility function. Instead, gaming is guided by their search for footing. This search for a secure situation differs according to each identity and its position on the network embedded in its social structure (Burt, 1992). For example, actors with more social connections tend to spend those social relationships to reach valuable resources, compared to other isolated actors. Here, it is in fact intended to imply access to resources and a trade-off or evaluation between the links. For example, a very popular woman or a man, a physician or an artist can make various calculations to reach their goals and more selectively, they may ignore their old networks.

For analytical purposes, in the concrete plane and second order point of view, each identity is consistently faces by three types of uncertainty (ambage, ambiguity and coincidence). This means gaming requires, be ready, nourish ambage, ambiguity and contingency. These three uncertainties are nothing more than crude/raw material or medium here. It is also necessary to consider the calculation of three uncertainties as a set (White, 2008:72; White etal. 2013 : 141).

In these transactions, "discipline" is used as an important concept. According to White, gaming / gambling or strategies emerge in different arrangements. The strict order in which these duties are organized, and to which they are linked, is called discipline. Each of these disciplines requires care and attention from the identities during game.

Three disciplines are possible. In addition, the type of uncertainty that dominates each type of discipline is also different. As a result, three disciplines and their corresponding types of uncertainty are shown in Table 1 (White, 1992; White et al., 2013:143):
A) Arena
B) Council
C) Interface

Arena discipline: In this type of discipline, the selection process and rules are important, as in sport competitions. The type of uncertainty that dominates here is ambiguity. This is because 
the rules are always open to manipulation, even if the role is fulfilled and predictable. As in the case of occupations, ambiguity is at the center of the filtering process in the arena (Abbott, 1981). Measures that guide this process have strategic priorities for identities. Every profession has rules and role requirements to follow. Breaking these rules can create skepticism about the profession. For example, although physicians swear that they value human life, they can flex the rules while fulfilling their professional roles. They can do private practice and play a better physician role with money. Nurses, they can benefit from patients by teaching the care services, hygiene, etc. Although they think that they actually help the patients, there is a rule breaking. Workers / employees can gain advantage by approaching political power.

Council discipline: It is the sort of discipline that resembles the prestige of an army or workplace. Here the ambage is the most dominant uncertainty principle. Key point here is the mobilization of identities according to prestige rankings. Here, according to prestige, the ability of an identity to act is to establish new roles and social relations to establish new coalitions.

Interface discipline: It is the kind of discipline that resembles commitment in preserving the quality of production. Here, contingency is the most dominant uncertainty principle. In this type of discipline, identities are dependent on external factors. For example, as in the firms on the market, there is a dependency on both the down steram of customers and the top or upsteram of suppliers (White, 2002; Godart and White, 2010). Likewise, physicians / nurses success depends on both health policies and attitudes of patients and their relatives. Another example is that the success of the teachings depends on both education policies and parents. As a result, the games are played in a three-dimensional area, as shown in Table 1. When researchers are determining turning points, that are changes, it is necessary to think together about both disciplines and types of uncertainty.

Table 1: Disciplinary processes and forms of uncertainty

\begin{tabular}{|l|l|l|}
\hline ARENA & COUNCIL & INTERFACE \\
\hline AMBUGUITY & AMBAGE & CONTINGENCY \\
SELECTION PROCESS & BALANCING & UNDERTAKING \\
RULES & PRESTIGE & QUALITY \\
\hline
\end{tabular}

According to White and Godart (2007 ;White et al.,2013: 142), a new regulatory rule put in place by the government, such as in the case of telecommunications, can change the role in the market, and this can either reduce or increase the ambage. Such a change requires actors to act. In the same way, a new pricing strategy may send signals that increase or decrease ambiguity in the market. It may not be necessary for the actors to take action in response to a change in ambage or ambiguity. However, not being in the action also exhibits a stance in the game. Also, if the latest arrivals to the market start to disappear at a different speed from a market or a neighboring market, this will change the level of contingency and will call a stance. Education and health policies in Turkey have become a scratch pad. There has also been increasing uncertainty about security and political regime. Parents, groups and organizations can not make plans for the future.

Strategies or games are the ways that are revealed by identities to cope with uncertainty and reduce risks (White et al., 2007:182). Risk reduction can be attributed to sophisticated insurance mechanisms. Indeed, some of them are in Schelling's (1980) Game Theory. But the game theory itself admits that uncertainties are possible when game rules are redefined. In the turbulent world to deal with uncertainties, acting is necessary to control uncertainty. White's 
(1992) Identity and Control is also written for this purpose. There is no world where there are no ambiguities, but it is pointed out that identities must work to control their uncertainties.

On the other hand, it is important to "bargain" during the interaction in terms of life in terms of Game Theory. More importantly, the basis of the bargaining process is the "communication". That is why we need to know the neo-functionalist Nicholas Luhmann and his Communication Theory.

According to Harrison et al. (2013:145), four social constructs can be helpful in showing how ambage and ambiguities are coordinated or exchanged. These are liminality, person, tournament and fashion, respectively.

Liminality: Victor W. Turner (1988). It is definedliminality as the environment in which the ambage most amount (maximum) of and ambiguity is least (minimum). According to Turner,b eing on the edge or on the coast is a mixed situation or a period. The scene and time at which the deepest values of the society emerged in the form of sacred drama or objects. When people skepticalin the most basic values about both people and public policies, ambiguity arises. According to White et al., (2013), Turner and his Works "Dramas, Fields and Metaphors, 1974" and "Anthrophology of Performance, 1988" are all about "ambiguity", and actually "ambage". In the case of liminality, social roles are still accepted, but their practice is suspended.

The rules are set in the society in a way that everyone understands. Klapp (1949) describes the process of putting rules here using the "court jester" and the "fool" metaphor. As stated by V. W. Turner, liminality is a concept developed by Gennep (1909;1960); originated as "threshold / limen" and means "rites of passage". This period is the time of crisis in which the foundations of social roles are questioned. In fact, Victor Turner extends the theory of Van Gennep (1909, 1960) to the book "Dramas, Fields and Metaphors", which he wrote in 1974, including the concept of social "drama".

Turner (1988:74-75) defines drama as a "aharmonic" and "disharmonic" social process that occurs in the context of social conflict. Typically, dramas have four faces in public action (cited in White et al.2013:146):

A) Breach: disobedience to social relations connected with regular rules.

B) Crisis: The period when the disobedience tends to expand. Each public crisis has some characteristics of being in the middle / threshold/limen. Because it is a social period between little or very stable in the social process. And it does not always have to be a sacred limen.

C) Redressive: Repair can vary from formal advice to legal proceedings, from personal advice and informal balancing or arbitration. Repairs also has a feature betwixt and between.

D) Reintegration: This last period is the period of recognition and reintegration of groups that are disturbed by each other, the integration or the faction being recognized as legitimate.

According to White et al. (2013:146), these typical drama recipes made by Turner can be reinterpreted using the notions of ambiguityand ambage. For example, in the period of disobedience (breach), whatever their point of departure, ambage and ambiguity increase. If identities acquire new positions by building alliances, the meaning of social drama / game is still uncertain. When reached to a certain ambagetreshold, the alliances become fully visible and positions are taken. As social action freezes, ambiguity increases, while ambage decreases. 
That's where the disobedience leads to the threshold. As the rules go into action, the meaning of the drama / game now becomes as follows: If the social drama is constantly in conflict with principles, persons and rules, the reflexivity will increase (Turner, 1978; 1988: 103). When the amabageis very high, the ambiguity is greatly reduced. In this case, identities go through a period of redress and reintegration in order to gain access to the new ambage and ambiguity balance.

According to White et al. (2013), crises and social drama moments can be compared to carnivals in New Orleans in the United States. Here, all kinds of social relations among individuals can be experienced by wearing masks. The rule of hiding identities in these environments is very simple. The social distances between people get out of the way and everyone is comfortable because they do not know each other. It can be recalled here that MichailBahtin's example of ensuring freedom of criticism of feudal lords in the name of throwing society's stress during carnivals.

After the crisis period, the system is directed to redressment. Here, the old rules are refreshed or new rules are created. In this period the ambage is very high. Since the rolls are not redistributed or redefined but their application is questioned, new rules emerge after the crisis ends. The actors deploy their strategies to enrich their safety situation in the "new space of possibles" with Bourdieu's terminology. The repair action, according to Turner (1988: 107), emerges to reduce / reduce the "space of possibles, and a new balance of forces occurs by allowing more stable and secure situations. Similarly, a person may have a relatively high ambage while having a low ambiguity about the meaning of the world.

That's why there are so many options for performance and creates connections. According to Turner (1988), "liminal phases" are more about doffing of masks , stripping of statuses and renunciation of roles and demolishing rather than preserving things.

In fact, White (2008; 2013:147) also provides information on tournaments that do not give more opportunities for stiffer and new interactions. The ambage is low in tuornament, but there is a lot of uncertainty about the contest and the competition. It is clear that the tournament is very different from the trade-off between the amabage and the ambiguous.

Finally,according to White et al.,(2013:148) the factors that lead to "contingency" are more likely to come from bio-physical conversions, as well as from a given social circle with social relations and meanings. Unexpected situations from this inner social circle are called "NETDOM" as abbreviated version of "Network-Domain" (Corona and Godart, 2010; Godart and White, 2010; Grabher, 2006). In fact, they are also interested in uncertainties about fashion. Fashion is medium contingecy because only two changes are made annually.

As a result, according to White et al. (2013:150-151), identities seeking secure status develop strategies that are disseminated in discipline. In strict order, every change in uncertainty creates a change in a "bifurcation" or "turning point" about the space of possibles with Bourdieu's terminology.All three of the uncertainties (ambage, ambiguity, consistency can be included in each discipline / strict order (arena, council, interface).

White and his colleagues (2013) first attempt is to distinguish between three types of ambiguity (ambage, ambiguity, and unexpectedness) and then link them the two relational structures in the form of social networks and meaning networks, in fact, they wanted to make the concept of "uncertainty" is key concept in social science research and relational paradigm. Their main debate is that these different uncertanity are structured by them at the same time 
as they are structuring their network dynamics and meanings. Understanding and measuring different uncertanity can be a very fruitful area for relational sociology. This will make it easier to understand the different levels and dynamics of the network analysis.

Indeed, it is very important that they indicate that their work is at an exploratory level and that they need to be improved. The promising aspects that are considered important within us and can be developed with other studies are (White et al., 2013:152):

A) The different forms of uncertainty can be further articulated. Different forms of contingency can be further improved as a result of social and biophysical transitions. Can be developed for originality in studies such as $\mathrm{PhD} /$ Master Thesis.

B) In cases of uncertainty, qualitative cases can be explored to show their relationship.

C) Quantitative surveys can help to test hypotheses about exchange between ambage and ambiguity in concrete settings.

D) All these studies can contribute to the full development of the model on the uncertainties and contribution to the relational paradigm.

\section{CONCLUSION}

Bourdieu is an important and powerful contribution to sociology in general and relational sociology specifically. He, while thinking relationally, has focused on cultural meanings in order to reveal relational patterns of meanings that link similarities and differences. Moreover, how double articulation of the meanings in the class and social structure was undoubtedly the subject of greatest interest to Bourdieu. But it has been repeatedly stated that Bourdieu's theory is better than his practice. For example, Mohr (2013) appreciated that Bourdieu showed how to measure social spaces. But he has also been criticized for being straight line. This is because the use of linear logic in understanding and interpreting the field space limits the application of his theory in a relational way. The examination of the topologically complex social field, depending on the methodological hegemony of the straight linear / linear logic, leads to the social processes being overlooked. Most importantly, this straight line view can also lead to some interaction systems being seen as superior. In other words, it is not possible to ignore the claim that Bourdie's dominant class fractions influence the rest of the society including culture. It is clear that this view is criticized as a consequence of linearity and the need for dialectical observation in terms of reciprocity.

Relational sociologists examined in this article try to use alternative or new unconventional concepts while trying to overcome the structure-individual duality. It is remembered that in Harrison White's work he used the concept of "identity" instead of individual, or "netdom" (network domain) in unexpected situations. Likewise Norbert Elias and his suggestion of "figurational sociology" can be considered in this context. Because when language is joined to analysis as an element of culture we start to communicate through metaphors.

In this context Norbert Elias (1978) and his "social figurations of people" can be seen as a kind of niche (Kivinen and Pyroinen, 2013). It means to describe these figurations as niches that support the individual members of the meaning of life and standards of action, and at the same time are influenced and changed by them. In fact, Elias criticizes functionalism and structuralism, and attempts to conceptualize the process of social relations in ancontinious and infinite process. In this context, the concept of figuration is a basic concept that N.Elias deals with in a similar way to the niches when examining the process of civilization.

Remember, the concept of figuration has been put forward to express that people exist together, not alone. Because naturally and through education socialized people become dependent on each other. Therefore, the idea of a society consisting of individuals, or an 
independent from the individuals, can not be accepted. Elias, in a book "Mozart,the Sociology of a Genius", seems to emphasize that both the daily life of the individual and the society can not be separated. According to him, social reality is a part of the mutual interaction and historical relations of people.

The concept of "figuriation" developed by Elias is important in order to explain the indispensable dependence of the individual and society on each other, especially in terms of the evolutionist perspective. Because "survival units" as a figurationprovide people accommodation, trust, nutrition and other vital conditions of life. In fact, Elias's concept of "living units" is crucial for relational sociology (Kaspersen and Gabriel, 2013), as it provides clear criteria for social analysts when separating or delineating the most relevant/ basic figures of the social life cycle.

From this point of view, some relationalist's (eg.Kivinen and Piironen) basic vision, from Dewey and Elias, that people need other people for their nature. In this sense there is in no way or placefor the rigid duality between the individual and society. At the same time, no one can live alone in a single island; no one is completely self-sufficient and can not exist independently of the outside world. This means that more people are dependent on each other and tend to live together. As Elias (2000) points out, social networks, from birth, through socialization, learning and education processes, increasingly develop within the figurations. However, these are the planned and unplanned dynamics in the long / great process of social life and intended or unintended interventions are always subject to change. In other words, the basic concept that Elias refers to in examining the process of civilization is the niches that can be conceptualized as "survival units" as the smallest unit of life. So, Elias and his thoughts are important and leading for relational sociology. Here, as Kivinen and Piiroinen (2013) pointed out, the similarities or translations of the concepts are the same. All of these should be perceived as an advantage for the reader.

There are a lot of various or different reletionalisms for social sciences today, as pointed out by the Finnish Kivinen and Piironien (2013), who criticized the ontologically groundedrelational sociology and wanted to draw the subject epistemologically on the methodology side. For example, there are some important differences in the work of Depelteau (2008), Mustafa Emirbayer (1997), Margaret Archer (1995), Charles Tilly (2001) and Pierre Bourdieu and Vacquant (1992). But it is necessary to know that rejection of the dualities are common and that it may not be new and that its first traces may be taken back to the American scientist John Dewey (1920). Because, as Dewey also emphasizes, the individual and society are not independent and opposing beings, but rather parts or different aspects of the same relational process of social life. Also, ontological and metaphysical views can tell us well that reality is ultimately relational. But more important and valuable is the methodological and instrumental analysis of the relationship in a non-metaphysical way. As is known, "instrumentalism" is the name given to the utilitarian(pragmatic) teaching of the American thinker John Dewey. Here, law, theory and theories are considered to be good and real when they are used as a tool or when they are successful, and bad and unreal when they are not successful.

Another important point that needs to be underlined is that Powell and Depeleteau (2013) use "social ontology" instead of "philosophical ontology" and they are trying to avoid metaphysics and use the notion of ontology differently than philosophy while discussing the possibility of a new paradigm in sociology. The basic stake of this inference is that while Depelteau (2013) advocates "deep" or "transactional" relational sociology and show a more materialist attitude thanM.Archer and R. Bhaskar -to base everything on the god as transcendent power- and therefore do not fall into idealism. 
Table 2 is organized to better describe the relational sociology given in detail in the previous sub sections. In this table comparisons are made generally between mainstream sociology and relational sociology in terms of , the logical reasoning, the unit of analysis, the basic idea, method, research techniques, causality, dichotomies, reification, epistemology, theory and practice, concepts, objectivity and rationality, scale; model development, It should also be noted that there is no hierarchical arrangement between such features. 
Table 2: Comparison of basic features of the mainstream and relational sociology

\begin{tabular}{|c|c|c|}
\hline Features & $\begin{array}{l}\text { Mainstream } \\
\text { Sociologists } \\
\text { Particularist\& } \\
\text { Holistic } \\
\text { Together } \\
\end{array}$ & $\begin{array}{l}\text { Generally relational } \\
\text { sociology } \\
\text { The following features are } \\
\text { shared intensively or } \\
\text { superficially }\end{array}$ \\
\hline Logical reasoning & $\begin{array}{l}\text { Deduction } \\
\text { Hypotetic deductive } \\
\text { Testing existing theories } \\
\text { (Top down / Formal Logic) }\end{array}$ & $\begin{array}{l}\text { Induction } \\
\text { Induction \& Move from } \\
\text { problem (Bottom up / } \\
\text { relational logic) }\end{array}$ \\
\hline Unit of Analysis & $\begin{array}{l}\text { Static social things, } \\
\text { situations; Predefined units } \\
\text { such as individual, } \\
\text { organization, society }\end{array}$ & $\begin{array}{l}\text { Dynamic, Fluid / } \\
\text { Processual\& Sustainable } \\
\text { (Social relationships in } \\
\text { everyday life as continuous. } \\
\text { Ex: Relations between } \\
\text { "niche" (Kivinen and } \\
\text { Prioinen, 2013) and "survival } \\
\text { units" (Elias, 2013) as the } \\
\text { smallest social unit ... Instead } \\
\text { of individuals ,analysis of } \\
\text { relations within living units } \\
\text { such as state. }\end{array}$ \\
\hline Basic thought & $\begin{array}{l}\text { Essentialism (Including } \\
\text { objectivity and subjectivism) }\end{array}$ & $\begin{array}{l}\text { Anti-essencialist\& Thinking } \\
\text { Reflexively }\end{array}$ \\
\hline Method & $\begin{array}{l}\text { Methodological } \\
\text { individualism \& } \\
\text { methodological holism }\end{array}$ & $\begin{array}{l}\text { Dynamic \& relational } \\
\text { methodology }\end{array}$ \\
\hline Research techniques & $\begin{array}{l}\text { Quantitative and variable } \\
\text { based. }\end{array}$ & $\begin{array}{l}\text { Qualitative \& Quantitative } \\
\text { together. Concept based. }\end{array}$ \\
\hline Cause-effect relationship & Determinist & $\begin{array}{l}\text { Uncertainty studies } \\
\text { \&Transactional. The } \\
\text { rejection of the one-way } \\
\text { determination. }\end{array}$ \\
\hline Duality / Dichotomies & $\begin{array}{l}\text { Society-individual; Structure- } \\
\text { action, Structure-agent ; } \\
\text { Macro-micro. Acceptance of } \\
\text { dual opposites. }\end{array}$ & $\begin{array}{l}\text { Analytical dualism } \\
\text { The effort of avoiding from } \\
\text { dichotomies }\end{array}$ \\
\hline Reification & $\begin{array}{l}\text { Acceptance of reification of } \\
\text { society }\end{array}$ & Rejection of the reification \\
\hline Epistemology & $\begin{array}{l}\text { Empirism\& Realism \& } \\
\text { Positivism; Humanism }\end{array}$ & $\begin{array}{l}\text { Pragmatism \& Irrationalism } \\
\text { \& Anti-humanism (important } \\
\text { in non-human / non-human); } \\
\text { Naturalism + Materialism }\end{array}$ \\
\hline Theory and practice & $\begin{array}{l}\text { Theory and practice } \\
\text { separately }\end{array}$ & $\begin{array}{l}\text { Theory and practice together } \\
\text { (Theory of Praxis: Bourdieu) }\end{array}$ \\
\hline Concepts & $\begin{array}{l}\text { Society, individual / agent, } \\
\text { structure etc. Predefined; } \\
\text { self-existent sociological } \\
\text { concepts }\end{array}$ & $\begin{array}{l}\text { Unusual new and dynamic } \\
\text { concepts such as niche, field, } \\
\text { figuration life world, life unit } \\
\text { networks, habitus, space of } \\
\text { possibles, netdoms }\end{array}$ \\
\hline Object and Objectivity / & Acceptance of objectivity \& & Avoidance from objectivity \\
\hline
\end{tabular}




\begin{tabular}{|c|c|c|}
\hline rationality & "Strategic objectivity" & $\begin{array}{l}\text { and subjectivity. (Avoiding } \\
\text { from strategic objectivity \& } \\
\text { liberating sociology that has } \\
\text { been passivated }\end{array}$ \\
\hline Scale & Macro-micro separation & Macro-micro together \\
\hline Change & $\begin{array}{l}\text { Hstorical linear ; } \\
\text { One-dimensional. }\end{array}$ & $\begin{array}{l}\text { Historical \& Geographical } \\
\text { (spatial); } \\
\text { The idea of multidimentional } \\
\text { change. Synchronic and } \\
\text { diachronic coexistence. Field } \\
\text { and space coexistence (field } \\
\text { space). Topological and } \\
\text { hodologicalanalyzes as social } \\
\text { fields. }\end{array}$ \\
\hline Language & $\begin{array}{l}\text { Conservative, status quo } \\
\text { based }\end{array}$ & $\begin{array}{l}\text { Figthing for liberation . } \\
\text { Defense and attack together. } \\
\text { Remember K. Polanyi's } \\
\text { concept of "double } \\
\text { movement". Also the } \\
\text { adoption of the idea that } \\
\text { language is a construction. }\end{array}$ \\
\hline Model development & $\begin{array}{l}\text { Rational actor and norm- } \\
\text { based Functionalism, } \\
\text { structuralism or statistical } \\
\text { variable based models. }\end{array}$ & $\begin{array}{l}\text { Search for transactual } \\
\text { models for interdisciplinary } \\
\text { work of natural and social } \\
\text { sciences, working to go } \\
\text { beyond linear models. }\end{array}$ \\
\hline
\end{tabular}

In Table 2, sociologies in general and relational were compared.This effort itself can be criticized as being a dualist.However, it can be considered as an analytical example of "analytical dualism" (Archer, 2013).Table 3 was prepared based on the argument that there are different relational sociologies (Depelteau, 2013)following the "Standpoint Theory" . It should not be forgotten in "radical sociology" (Powell, 2013), which is not included in this table.

There are a number of positive and negative evaluations on relational sociology, starting with the debate on the beginning of domestication (Emirbayer, 2013) because of its increasingly lost its warrior characteristics.According to Depelteau (2013), which has important studies on relational sociology, there is in fact no way to make a single relational sociology. Depelteau (2013) found that there were three types of relational sociology after examining the work done in this respect. These are a) deterministic, b) co-deterministic, and finally c) deep relational sociology. 
Table 3. Comparative three relational sociology

\begin{tabular}{|c|c|c|c|}
\hline Features & $\begin{array}{l}\text { 1.Determinist / } \\
\text { Structuralist } \\
\text { (Relational } \\
\text { sociology) }\end{array}$ & $\begin{array}{l}\text { 2.Dialectic (Co- } \\
\text { determinist) Relational } \\
\text { sociology }\end{array}$ & $\begin{array}{l}\text { 3. Deep or } \\
\text { transactional relational } \\
\text { sociology }\end{array}$ \\
\hline $\begin{array}{l}\text { Leading thinkers } \\
\text { (relational } \\
\text { thinking without } \\
\text { relational } \\
\text { sociology) }\end{array}$ & $\begin{array}{l}\text { G. Simmel } \\
\text { E.Durkheim } \\
\text { T. Parsons } \\
\text { N.Luhmann } \\
\text { R. Collins } \\
\end{array}$ & $\begin{array}{l}\text { A. Giddens } \\
\text { P.Bourdieu } \\
\text { P.Bergerve } \\
\text { T. Luckmann }\end{array}$ & $\begin{array}{l}\text { M. Weber } \\
\text { H. Blumer } \\
\text { B. Latour } \\
\text { H. Becker }\end{array}$ \\
\hline $\begin{array}{l}\text { Current } \\
\text { representatives }\end{array}$ & $\begin{array}{l}\text { B. Wellman \& } \\
\text { Berkowitz (1997) }\end{array}$ & $\begin{array}{l}\text { M.Archer } \\
\text { P. Donati } \\
\text { R. Bhaskar } \\
\text { D. Elder-Vaas }(2007,2010)\end{array}$ & $\begin{array}{l}\text { A.King } \\
\text { F. Depelteau }\end{array}$ \\
\hline Key features & $\begin{array}{l}\text { It is a current } \\
\text { derivative of } \\
\text { positivist sociology. } \\
\text { Not the individual, } \\
\text { but the systems } \\
\text { come } \\
\text { first.Prioritize } \\
\text { structural } \\
\text { constraints. They } \\
\text { assume social } \\
\text { constructs and } \\
\text { their structural } \\
\text { and causal forces } \\
\text { as determinism. }\end{array}$ & $\begin{array}{l}\text { Defend "analytical } \\
\text { dualism". In other words, } \\
\text { the structure and the } \\
\text { agents in the society have } \\
\text { separate powers.For the } \\
\text { sake of analysis, society } \\
\text { and human / individual } \\
\text { are discriminated.There is } \\
\text { a dialectical relationship } \\
\text { between man and } \\
\text { society.As a product, the } \\
\text { society returns and affects } \\
\text { its producers, that is, it } \\
\text { affects and even imposes } \\
\text { on people. The main } \\
\text { objective is to show that } \\
\text { the person is both } \\
\text { community-dependent } \\
\text { (passive) and self- } \\
\text { sufficient } \\
\text { (active). }\end{array}$ & $\begin{array}{l}\text { Individuals / actors do } \\
\text { not associate with the } \\
\text { social structure. } \\
\text { Humans can only } \\
\text { relate to other human } \\
\text { and non-human beings. } \\
\text { Individuals are social } \\
\text { beings. Our human / } \\
\text { human behaviors do } \\
\text { not come from the } \\
\text { objects themselves. } \\
\text { Our human behavior } \\
\text { comes from our } \\
\text { perceptions of objects } \\
\text { (see Symbolic } \\
\text { Interactivity). Deep } \\
\text { relational sociologists } \\
\text { therefore do not use } \\
\text { the concept of agency. } \\
\text { It is important to } \\
\text { examine } \\
\text { interdependence / } \\
\text { transactionalprocesses. } \\
\text { It is essential that B } \\
\text { does not exist without } \\
\text { A, or that A and B } \\
\text { depend on each other } \\
\text { (transacting). }\end{array}$ \\
\hline Basic criticism & $\begin{array}{l}\text { Neglecting the } \\
\text { individual in front } \\
\text { of the structure to } \\
\text { maintain the old } \\
\text { determinist views. } \\
\text { To be "old wine in } \\
\text { the new glass". "To } \\
\text { reproduce what } \\
\text { exists". To make an }\end{array}$ & $\begin{array}{l}\text { They seem to care about } \\
\text { some extent with agent; } \\
\text { they are similar to the old } \\
\text { Durkheimian determinist } \\
\text { views. Partial "reification". }\end{array}$ & $\begin{array}{l}\text { There is not a single } \\
\text { deep sociology, at least } \\
\text { two different types. } \\
\text { A) "Deep" Relational } \\
\text { Sociology (A. King, H. } \\
\text { Blumer, H. Becker, B. } \\
\text { Latour) } \\
\text { B) "Transactional RS.. } \\
\text { (F. Depelteau) }\end{array}$ \\
\hline
\end{tabular}




\begin{tabular}{|c|c|c|c|}
\hline & $\begin{array}{l}\text { absolute } \\
\text { "reification" }\end{array}$ & & $\begin{array}{l}\text { There are also } \\
\text { C.Powel and "Radical" } \\
\text { relational sociology. } \\
\text { Rejection of all kinds of } \\
\text { reification. }\end{array}$ \\
\hline $\begin{array}{l}\text { Basic review } \\
\text { unit }\end{array}$ & $\begin{array}{l}\text { Empirical relations } \\
\text { between concrete } \\
\text { actors }\end{array}$ & $\begin{array}{l}\text { Because structures are } \\
\text { relations between } \\
\text { concrete actors, } \\
\text { examination units are } \\
\text { concrete actors. }\end{array}$ & $\begin{array}{l}\text { Rejection of subject \& } \\
\text { agent \& agency. Go } \\
\text { beyond the subjectivity } \\
\text { and objectivity.The } \\
\text { "relations" between } \\
\text { small social units or } \\
\text { transaction areas } \\
\text { connected to each } \\
\text { other are examined } \\
\text { like a niche or a living } \\
\text { unit or a lifeworld. }\end{array}$ \\
\hline $\begin{array}{l}\text { Common aspects } \\
\text { of the three RS. }\end{array}$ & $\begin{array}{l}\text { The idea that a new } \\
\text { paradigm is needed }\end{array}$ & $\begin{array}{l}\text { The idea that a new } \\
\text { paradigm is needed }\end{array}$ & $\begin{array}{l}\text { The idea that a new } \\
\text { paradigm is needed }\end{array}$ \\
\hline $\begin{array}{l}\text { Philosophical } \\
\text { ontology } \\
\text { (Metaphysics) or } \\
\text { Social ontology / } \\
\text { Thought on } \\
\text { scientific basis. }\end{array}$ & $\begin{array}{l}\text { There are } \\
\text { metaphysical } \\
\text { aspects. }\end{array}$ & $\begin{array}{l}\text { Metaphysics. In particular, } \\
\text { M.Archer and R. Baskar } \\
\text { and their critical } \\
\text { realismassume that "God" } \\
\text { is the foundation of } \\
\text { everything. }\end{array}$ & $\begin{array}{l}\text { Avoiding metaphysical } \\
\text { considerations; To } \\
\text { accept that we have } \\
\text { been living in this } \\
\text { universe for a short } \\
\text { period of time (do not } \\
\text { fall into the trap of } \\
\text { idealism). Social } \\
\text { ontology\& Deep } \\
\text { Relational Sociology. } \\
\text { It is pragmatism where } \\
\text { there is no separation } \\
\text { of mind-body. }\end{array}$ \\
\hline
\end{tabular}

The aim of White and colleagues (2013), which provides the theoretical framework for some of the empirical studies in this book, is to clarify the dynamics of social networking and semantic networks in the context of "uncertainty" in relation and meaning. Their goal is thus to develop a broader and more comprehensive relational theory of social formation. The determination of "turning points" is the basic aim of the relevant relational theory. The notion of turning points resembles the "breakdown points" Foucault prefers in his archeology of knowledge.

This can be said to be a transition to a new situation with significant effects occurring during the course of events, or a radical changes like railway cutting. For example, on September 11, 2001, the World Trade Center bombing is a breakdown or turning point. Because the United States, known for its respect for human rights and freedoms, has been observed to have suspended all the freedom. The present government in Turkey is a turning point. The transformations in education such as abolishing private establisments preparing students for various exams, health performance system applications, military-civilian, community relations, military interventions all can be considered as breaking points in Turkey.. In addition, developments in technology can not be ignored. Smartphones and the conditions provided by the Internet have changed communication networks both in form and in content. 
In fact, although there are a lot of new model experiments in the literature in terms of relational sociology, they are not very different from previous theories, nor are they revolutionary, despite all the striking novelty allegations, even Fuhse's (2013:181-200). Symbolic Interactionism and Dramaturgical Sociology, System Approach, Phenomenological Knowledge Sociology and Symbolic Interactionism have very similar aspects. Fuhse(2013) wants to make use of the previous ones by adding missing points to develop a more competent theory. For this purpose, he defines what social "relationships" are, in the sense of relational expectations. He also demonstrates how he benefits from or uses the cultural model of social relations. He aims to build a bridge between sociological network analysis and his model and never thinks of leaving them. For example, takes advantage of Luhmann's Communication Theory while achieving a relatively simple model of "relation". Moving from different bases, such as "interaction" (E. Gofman), "action" (T. Parsons) or "Exchange" (P. Blau) does not makechange much in this model. They are becoming more important in the understanding of everyday life as well as creating more complexity in mental situations and processes.

As "Fuhse" (2013:185 ) carefully underlines, "relationships" somewhat different from relations arises between two people and is a special case of social relations in the more general level.

The "expectations" arise from the communication between A and B. "Communication" is the basic process that needs to be examined here. The determinants of expectations are "culture". The values and thoughts about relational frameworks, friendship, and patronage vary from culture to culture and change over time in the same culture. Sociologically, we need to add technology into the culture as material culture. In the professional medical culture, the "patronage associations" have been reduced or differentiated with the excessive specialization and bureaucratization. Because physicians have started to be workers. The use of advanced technology has also destroyed traditional doctor-patient relationships. However, patronage is still observed in both husband and wife and academic advisor-student relations. This may be the case in art. Because the traditional master-apprentice relationship provides learning. In addition, the relationship between men and women can be searched. Because the family structure and relationships are largely transformed by women working outside the home.

Relational sociological studies have been carried out as "mixed designs " in quantitative and qualitative contexts, as well as "structure / system" (Parsons and Luhmann) of Structural Functional Sociological Approaches apart from some important new concepts in uncertainty studies; It would not be wrong to say that "Comprehensive Cultural Sociology" has been made in a way that is well known, using the structure and agent symbolic interactionism (E. Goffman) and culturefrom Bourdieu(Edles, 2002).

It is not wrong to say that the best and shortest way of understanding what relational sociology is is largely the work of Elias's process sociology and H.White's ambiguity studies as well as the studies of concrete problems through Grounded Theory methodology (Creswell, 1997; Kasapoglu, 2015). 


\section{References}

Abbott, A.D. (1981) Status and Status Strain in the Profession. American Journal of Sociology 80: 819-835Abbott, A.D. (2001) Time Matters: On Theory and Method. Chicago: Chicago UP.

Allport, F (1955) Theories of Perception and the concept of Structure. New York: John Wiley and Sons.

Archer, M.S. (1998) Realist SocialTheory: The Morphogenetic Approach. Cambridge: Cambridge UP.

Atkinson, P.,Hammersley, M.(2006) Ethnography. London: Routledge

Baur, N. (2008) Taking Perspectivity Seriously. Historical SocialResearch33:191-223

Baur, N. (2010) Making Process Generated Data in Market Sociology. Quality and Quantity19:1-20.

Baur, N.,Lamnek, S.(2007) Multivariate Analysis. In Encyclopedia of Sociology (ed.G.Ritzer). Oxford: Blackwell.

Baur, N.,Ernst, S. (2011)Towards a Process-oriented Methodology: Modern Social Science Research Methods and Norbert Elias's Figurational Sociology. Sociological Review 117-139.

Bearman, P.S.,Faris, R., Moody, J. (1999) Vlocking the Future: New Solutions for Old Problems in Historical Social Science, Social Science History 23: 501-535.

Bechelard, G. (1964) ThePoetics of Space.(Trans. M. Jolas ve J.R. Stilgoe). Boston: Beacon.

Beckman, C.M.,Haunschils, P.R., Phillips, D.J. (2004) Friends or Strangers ? Firm -Specific Uncertainty, Market Uncertainty and Network Partner Selection, Organization Science 15: 259-275.

Bickerton, D.(2009) Adam's Tongue: How Human Made Language., How Language Made Human. New York: Hilland Wang.

Bourdieu, P.(1977) Outline of a Theory of Practice.. Cambridge: Cambridge UP.

Bourdieu, P. (1983) The Field of Cultural Production, or the Economic World Reversed. Poetics 12:311-356.

Bourdieu, P. (1984) Distinctions: A Social Critiques of the Judgement of Taste. Cambridge MA.

Harvard UP. Bourdieu P.(1985) The Genesis of the Concept of Habitus and Field. Sociocriticism, 2: 11-24.

Bourdieu, P. (1987) The Force of Law: Toward A Sociology of the Juridical Field. Hasting Journal of Law 38:209248.

Bourdieu, P. (1988) Homo Academicus. Stanford: Stanford UP.

Bourdieu, P. (1991) Genesis and Structure of the Religious Field. Comparative Social Research 13: 1-44.

Bourdieu, P. (1998) Practical Reason. Stanford: Stanford UP

Bourdieu, P.,Passeron, J.C. (1977) Reproduction: InEducation, Society and Culture. Beverley Hills: Sage.

Bourdieu, P.,Wacquant, L. (1992) An Invitation to Reflexive Sociology. Chicago: Chicago UP.

Bourdieu, P. (2015) Ayrım: Beğeni Yargısının Toplumal Eleştirisi (Distinction: Social Critics of Tastes) (Trans. D.Frrat and G. Berkkurt). Ankara: Heretik.

Brandom, R.B.(2004) The Pragmatist Enligthment and Its Problematic Semantics. European Journal of Philosophy 12: 1-16.

Breiger, R.L. (2000) TheTool Kit for Practice Theory. Poetics 27: 91-115.

Breiger, R.L. (2009) The Analysis of Networks.İç. The Sage Handbook of Data Analysis.(ed. M. Hardy and A. Bryman. Los Angeles: Sage (pp.505-526).

Bryman, A.( 2006) (ed.) Mixed Methods. London: Sage.

Burt, R. (1992) StructuralHoles: The Social Structure of Competition. Cambridge, MA.: Cambridge UP.

Calhoun, C.,Lipuma, E., Postone, M. (1993) Bourdieu: Critical Perspectives. Chicago: Chicago UP.

Cassirer, E. (1910;1953) Substance and Function(çev. W. C. Swabey and M.C. Swabey) New York: Dover.

Caws,P. (1988) Structuralism: The Art of Intelligible. Berkeley, CA: California UP.

Chomsky, N. (2002) On Nature and Language. Cambridge: Cambridge UP.

Collins, R. (1998) TheSociology of Philosophies. A Global Theory of Intellectual Change. Cambridge, MA: Harvard UP.

Corona,V.,Godart,F. (2010) Network-Domains in Combat and Fashion Organizations. Organizations 17:283-304. 
Creswell, J.W., Vicki,L.,Plano,C. (2006) Designing and Conducting Mixed Methods research, London: Sage. Çeğin,G.,Göker,E. (2012) (ed.) Özcülüğün Tasfiyesi: İlişsisel Sosyolojide Yeni Yaklaşımlar(Discharging of Essentialism :New Approaches in Relational Sociology) İstanbul: Notabene.

Dasgupta, P. (1988) Trust as a Commodity İç. Trust: Making a Breaking Co-operative Relations. /ed. D. Gambetta). Oxford, UK: Basil Blackwell. (pp.49-72).

Deacon, T.W. (1997) The Symbolic Species: TheCo-evaluation of Language and the Brain. London: PenguinBooks.

De Certeau,M. (1984) The Practice of Everyday Life. Berkeley, CA: California UP.

Depelteau, F. (2008) Relational Thinking: A Critique of Co-deterministicTheories of Structure and Agency. SociologicalTheory 26: 51-73.

Depelteau, F.,Powell, C. (2013) Applying Relational Sociology: Relations, Networks and Society. New York: Palgrave\&Macmillan.

Dewey, J.(1922;1983) The Human Nature andConduct. The Middle Works of John Dewey. (ed. J.A. Boydston) Carbondale: Southern Illinois UP.

Dewey, J. (1920;1988) Reconstruction in Philosophy and Essays. The Middle Works of John Dewey. (ed. J.A. Boydston) Carbondale and Edwardsville: Southern Illinois UP.

Dewey, J. (1925;1988) Experience and Nature. The Later Works of John Dewey. Carbondale and Edwardsville: (ed. J.A. Boydston) Southern Illinois UP.

Dewey, J. (1938;1991) Logic, TheTheory of Inquiry. The Later Works of John Dewey. Carbondale and Edwardsville: (ed. J.A. Boydston) Southern Illinois UP.

DiMaggio, P.J.,Mohr, J. W. (1985) Cultural Capital, Educational Attainment and Marital Selection. American Journal of Sociology 90: 1231-1261.

Donald, M.(2001) MindsoRare: TheEvolution of Human Consciousness. New -York: W.W. Norton.

Durham, W.H. (1991) Coevolution: Genes, Culturesand Human Diversity. Stanford: Stanford UP.

Edles, L. D.(2002) CulturalSociology in Practice: 21 st.CenturySociology. Oxford: Blackwell.

Elias, N (1939; 2000) The Civilizing Process: Sociogenetic and Psychogenetic Investigations. (Trans. E.Jephcott. Ed. E. Dunning and J. Goudsblom ve S.Mennel). Singapore: Blackwell.

Elias,N.(1969) The Court Society: CollectedWorks,Vol. 2, Dublin: UCD.

Elias, N.(1970; 1978) What is Sociology?(Trans. S.Mennel and G. Morrissey).New York: Columbia UP.

Elias,N.(1977) Towards a Theory of Social Process, Collected Works, Vol.16, Dublin: UCD.

Elias,N. (1978) The Concept of Everyday Life. Collected Works,Vol.1,. Dublin: UCD.

Elias,N.(1983) A Diagnosis of Present-day Sociology, Collected Works, Vol.16,Dublin,UCD.

Elias,N. (1986) Figuration. CollectedWorks,Vol.16. Dublin, UCD.

Elias,N. (1987) Involvement and Detachment, Collected Works, Vol.8, Dublin: UCD.

Elias,N.(1995) Technization and Civilization.Collecetd Works, Vol. 15,Dublin,UCD.

Elias,N.,Scotson,J.L. (1965) The Established and Outsiders. Collected Works, Vol.4.Dublin, USC.

Elias,N.(2000) Mozart bir Dahinin Sosyolojisi (Mozart: The Sociology of Genious Man (Trans. Y.T.Kılıç). İstanbul: Kabalc1.

Emirbayer, M. (1997) Manifesto for a Relational Sociology. American Journal of Sociology 103: 281-317.

Ernst,S. (2013) From Blame Gossip to Praise Gossip. European Journal of Women's Studies 10: 277-99.

Ernst,S. (2009) Using Qualitative Content Analysis of Popular Literature for Uncovering Long Term Social Processes. Historical Social Research 34: 252-269.

Fetterman, D.M.(1998) Ethnography. İç. Handbook of Applied Social Research Methods (ed.L. Bickman and D.J. Rog) London: Sage.(pp.473-504).

Fuhse,J.A. (2013) Social Relationships Between Communication, Nerwork Structure and Culture. İç İç. Applying Relational Sociology: Relations, Networks and Society (eds. F. Depelteau and C. Powell). New York: Palgrave (pp.181-2006). 
Fligstein,N.,McAdam,D. (2012) A Theory of Fields. Oxford: Oxford UP.

Gargani, A.G. (2011) Pragmatic View of Language: From Trutht other Meaning of Truth. İç. The Philosophy of R. Rorty. (ed. R.E. Auxier and L.E. Hahn) La Selle: Open Court.(pp.175-192).

Gerth, H.,Mills, C.W. (1953;1964) Character of SocialStructure: A Psychology of SocialInstitutions. New York: Harcourt\&Brace. Godart, F.C.,

White, H. C. (2010) Switching Under Uncertainty: The Coming and Becoming Meaning. Poetics 38:567-586.

Goffman, E. (1959) The Production of Self in Everyday Life. Gardencity, NY: Doubleday.

Goudsblom, J.,Mennell, S.(1997) The Norbert Elias Reader. Oxford: Blackwell.

Grabher, G. (2006) Trading Routes, Bypasses and Risky Intersections: Mapping theTravels of Networks' Between Economic Sociology and Economic Geography 30: 163-189.

Habermas,J.(1972) Knowledge and Human Interests. London: Heinemann.

Hebdige, D. (1979) Subculture: The Meaning of Style. London: Routledge.

Hedström,P.,Ylikosk.P. (2010) Causal Mechanisms in Social Sciences, Annual Review of Sociology 36:49-67.

Jahoda,M.,Lazersfeld, P.F., Zeisel, H. (1933;2012) Marienthal. New Brunswick, NJ: Transaction.

Kasapoğlu, M.A., (2015) Özne Hayatı Konuşunca: Sosyolojide Temellendirilmiş Kuram İncelemeleri (When the Subjact Speaks : Ground Theory Studies in Sociology) . Ankara: Ayrıntı .

Kaspersen,L.B.,Gabriel,N.(2013) Survival Units as the Point of Departure for a Relational Sociology. In. Applying Relational Sociology: Relations, Networks and Society (eds. F. Depelteau and C. Powell). New York: Palgrave (pp.50-81).

Kıray, M.B. (1964) Ereğli, Ağır Sanayiden Önce Bir Sahil Kasabası: Kuramsal Boyutlar (Eregli : A Seashore Town Before Heavy Industry ). Ankara:DPT.

Kivinen,O.,Piiroinen,T. (2004) The Relevance of Ontological Commitments in Social Sciences: Realist and Pragmatic Viewpoints, The Journal for the Theory of Social Behavior 34:231-248.

Kivinen,O.,Piiroinen,T. (2006) Toward Pragmatist Methodological Relationalism: From Philosophizing Sociology to Sociologizing, Philosophy. Philosophy of SocialSciences 36: 303-329.

Kivinen,O., T. Piiroinen (2007) Sociologizing Metaphysics and Mind: A Pragmatist point of View on the Methodology of the Social Sciences, Human Studies 30:97-114.

Kivinen,O.,Piiroinen,T. (2012) On the Distinctively Human : Two Perspectives on the Evolution of Language and Conscious Mind, Journal of Social Theory and Social Behavior 42:87-105.

Kivinen, O.,Piioinen,T.(2013)Human Transaction Mechanisms in Evolutionary Niches: A Methodological Relationalist Standpoint.In. Applying Relational Sociology: Relations, Networks and Society(eds. F. Depelteau and C.Powell). New York:Palgrave (pp.83-101).

Klapp,O.E. (1949) TheFool as a SocialType. TheAmericanJournal of Sociology 55: 157-162.

Kuzmics, H. (2009) Concept of Validating theTheoretical Potential of Historical Sources, Historical Socal Research 34:270-305.

Laland,K.,Sterelny, K. (2006) Prepective: Seven Reasons (Not) to Neglect Niche Construction. Evolution: International Journal of Evolution 60: 1751-1762.

Lewin, K. (1951) FieldTheory in SocialSciences. New York: Harper.

Machamer, P,L.,Darden, L., Crawer, C.F.(2000) Thinking About Mechanisms, Philosophy of Science 67:1-25.

Mennel,S. (1998) Norbert Elias: An Introduction. Dublin:UCD.

Mohr, J.W., White, H.C.(2008) How to Model an Institution? TheoryandSociety 37: 485-512.

Mohr, J. W. (2013) Bourdieu's Relational Method in Theory and Practice: From Fields and Capitals to Network and Institutions. In. Applying Relational Sociology: Relations, Networks and Society (eds. F. Depelteau and C. Powell). New York: Palgrave (pp.101-135).

Palmer, V.M. (1928) FieldStudies in Sociology. Chicago: Chicago UP.

Powell, C.,Depelteau, F.(2013) Conceptualizing Relational Sociology: Ontological and Theoretical Issues. New York: Palgrave\&Macmillan. 
Ramazanoglu, C.,Holland, J. (2002) Feminist Methodology: Challenge andChoices. New Delhi: Sage.

Schelling, T.C. (1960) TheStrategy of Conflict. Cambridge, MA: Harvard UP. Somers, M. (1998) Weare No Angels: Realism, Rational Choice and Relationality in Social Sciences, American Journal of Sociology 104:722-784.

Strauss,A.L.,Corbin,J. (1990) The Basics of Qualitative Analysis: Grounded Theory Procedures and Techniques. London: Sage.

Tilly, C. (2001) Relational Origins of Inequality, AnthropologicalTheory 1: 355-372.

Turner, V.W. (1974) Dramas, Fields and Metaphors, Symbolic Action in Human Society. Ithaca N.Y: Cornell UP.

Turner,V.W. (1988) Anthropology of Performance. New York: PAJ.

Van Gennep, A. (1909;1960) The Rites of Passage. Chicago: Chicago UP.

Wallerstein, I. (1999) The Heritage of Sociology: The Promise of Social Sciences, Current Sociology, 47:1-37.

Weber,M. (1947) From Max Weber: Essays in Sociology (Trans.. H.Gerth and C.W.Mills) New York: Oxford University Pres.

Wouters,C. (2004) Sex and Manners: Female Emancipation in the Wesr. 1890-2000.London: Sage.

White, H.C. (1992) Identity and Control: A Structural Theory of Social Action. Princeton N.J.: Princeton UP.

White, H.C. (2002) Marketsfrom Networks: Socioeconomic Models of Production. Princeton N.J.: Princeton UP.

White, H.C. (2008) Identity and Control: How Social Formations Emerges. Princeton N.J.: Princeton UP.

White, H.C.,Godart, F.C., Corona, V.P. (2007) Mobilizing Identities: Uncertainty and Control Strategy, Theory, Culture and Society 24:181-202.

White, H.C, Godart, F.C.,Thiemann, M. (2013) “Turning Points and the Space of Possibles: A Relational Perspective on the Different Forms of Uncertainty". In. Applying Relational Sociology: Relations, Networks and Society. ( eds. François Depelteau and Christopher Powel). New York: Palgrave (pp.137-154) 